\title{
Counterparty Credit Risk in 0TC Derivatives under Basel III
}

\author{
Mabelle Sayah ${ }^{1,2,3}$ \\ ${ }^{1}$ Group Risk Management, Bank Audi S.A.L., Beirut, Lebanon \\ ${ }^{2}$ LSAF, Univ Lyon, UCBL, Lyon, France \\ ${ }^{3}$ Mathematics and Applications Laboratory, EGFEM, Saint Joseph University, Beirut, Lebanon \\ Email: mabelle.sayah@univ-lyon1.fr
}

How to cite this paper: Sayah, M. (2017) Counterparty Credit Risk in OTC Derivatives under Basel III. Journal of Mathematical Finance, 7, 1-38.

https://doi.org/10.4236/jmf.2017.71001

Received: October 18, 2016

Accepted: December 26, 2016

Published: December 30, 2016

Copyright (C) 2017 by author and Scientific Research Publishing Inc. This work is licensed under the Creative Commons Attribution International License (CC BY 4.0).

http://creativecommons.org/licenses/by/4.0/

\begin{abstract}
Recent financial crises were the root of many changes in regulatory implementations in the banking sector. Basel previously covered the default capital charge for counterparty exposures however, the crisis showed that more than two third of the losses related to this risk emerged from the exposure to the movement of the counterparty's credit quality and not its actual default therefore, Basel III divided the required counterparty risk capital into two categories: The traditional default capital charge and an additional counterparty credit valuation adjustment (CVA) capital charge. In this article, we explain the new methodologies to compute these capital charges on the OTC market: The standardized approach for default capital charge (SA-CCR) and the basic approach for CVA (BA-CVA). Based on historical calibration and future estimations, we built internal models in order to compare them with the amended standardized approach. Up till June 2015, interest rate and FX derivatives constituted more than $90 \%$ of the traded total OTC notional amount; we constructed our application on such portfolios containing and computed their total counterparty capital charge. The analysis reflected different impacts of the netting and collateral agreements on the regulatory capital depending on the instruments' typologies. Moreover, results showed an important increase in the capital charge due to the CVA addition doubling it in some cases.
\end{abstract}

\section{Keywords}

Counterparty Credit Risk, SA-CCR, CVA, OTC Derivatives, Basel III

\section{Introduction}

Derivatives market witnessed an important bloom in recent decades due to their increasing utility in our financial markets. Several typologies and complexity le- 
vels of such instruments are used either in a regulated exchange traded manner or in an over the counter fashion. Instruments could be swaps, options, futures, forwards... Exchange traded activity started in 1970 following certain rules and "standardized" formats whereas over the counter (OTC) market came in 1990 as an "irregular" market with various customizable trades; therefore it is a more risk vulnerable environment. OTC market has a larger volume due to the higher profit margin and wider bid-ask spreads. Trying to reduce the risk on the OTC market, clearing houses were created in order to give all the counterparties a guarantee not to have any open positions and to force applications of the agreed upon rules.

Derivatives hold several types of risks such as market, liquidity and credit, however the credit risk in such instruments is not the typical credit risk that we encounter when passing a loan; it is the counterparty credit risk. The counterparty credit risk differs from the traditional credit risk by two points: The bilateral risk profile and the variation of the exposure depending on market and counterparty behavior. Counterparty credit risk is the risk taking into account the exposure of the financial institution to the counterparty if this latter defaults or has its credit quality devaluated. Recent crises emphasized the faulty practices regarding the OTC derivatives capital charge computation from a counterparty credit risk point of view: Starting with the collapse of Lehman Brothers and several near and full collapses of banks all over the United States, United Kingdom and Europe, the counterparty risk gained now the same importance as the major well-known risks (market, liquidity, operational...). Counterparty credit risk has gained importance making it a central need in several areas of the banking workflow: Pricing OTC products, computing the capital charges, managing exposures to different counterparties and finally stating the conditions of a certain deal concerning the initial margin or collateral... Basel II had implemented methods to compute the default capital charge of the counterparty credit risk beard in derivatives however in the subprime crisis two thirds of the losses did not result from such category of counterparty risk. A new risk source was highlighted: the risk resulting from the credit valuation of the counterparty noted the credit valuation adjustment risk (CVA). In this paper our aim is to describe the current OTC market, to briefly note the previously applied regulatory methods for the counterparty credit risk then to explain and apply the new methods in order to compute the capital requirements on typical portfolios. The paper proposes also an internal approach to compute the same figures based on historical behavior and future market experts' estimations. Section I introduces the counterparty credit risk, Section II details the default capital charge whereas Section III details the CVA risk capital charge. Section IV presents the application of such techniques compared to internal approaches on sample portfolios and finally Section $\mathrm{V}$ concludes on the results.

\section{Counterparty Credit Risk}

Counterparty Credit risk is a major risk faced on the OTC market. It covers two 
facts: the defaults of the counterparty or the decrease in its credit quality as described in [1]. In both scenarios, the bank would try to replace the instrument held or re-evaluate its worthiness. In order to compute this "replacement cost" and "potential future exposure" different factors are involved such as: Mark-tomarket exposure, liquidity risk following a counterparty's default, operational risk as in the process of managing the positions after a change had occurred or even in managing the margins or collaterals of a certain agreement and finally legal risk related to enforcement for the application of the deals conditions. As the use of derivatives has grown, especially on the OTC market, regulators are continuously trying to implement new approaches that reflect as adequately as possible the counterparty risk englobed by these instruments and therefore making their approaches more and more sophisticated, see [2].

\subsection{Transition to Basel}

In an attempt of improving capital framework for OTC derivatives under Basel III method presented in [3], several reforms were put in place:

- Wrong way Risk is more adequately evaluated by not taking recoveries in the loss given default (LGD) computation (the amount lost in case of the counterparty's default).

- The computation of the portfolio exposure is required to take into account a stressed period values (in LGD calibration).

- New method for collateralized transactions evaluations to capture the exposure over a full year of inception.

- Standards for initial margining have been strengthen.

- The asset value correlation parameter was increased by $25 \%$ to reflect the correlations between financial institutions raising the risk weights.

Another important change in Basel III is the addition of a credit valuation adjustment (CVA) capital charge to capture the risk of mark to market losses on the expected counterparty credit risk, this is amply described in [4]. Total losses from CVA were double the losses from defaults (66\% from CVA and only $33 \%$ of the losses are due to defaults). The CVA capital charge is expected to double the capital charge for derivatives however, banks are not going to be asked to put any additional CVA charge if the derivatives are centrally cleared: This is an incentive to clear through a central counterparty clearing house (CCP).

\subsection{Default Capital Charge Computation}

All banks are required to hold capital against the variability in the market value of their OTC instruments: They need to capitalize for default risk. As it is well known for Basel amended approaches two possibilities are entitled: A standardized approach and an internal model implementation. In the following, we are going to discuss briefly the characteristics and method scheme of each of these methods in order to apply them in the following part of this work and compare their figures. 


\subsubsection{Standardized Counterparty Credit Risk Approach (SA-CCR)}

SA-CCR is the new standardized approach for computing default counterparty credit risk presented in the BCBS document [5]. It was presented and revised by April 2014 and is in order to be implemented by January 2017. Different papers described this method such as [6], in our work we try to summarize and apply it on different portfolios under different conditions in order to understand the behavior of this practice.

Main objectives of this method implementation were to be:

- Suitable to be applied on different kinds and specifications of derivatives transactions

- Easy and simple implementation techniques

- Better than the methods that preceded

- More risk sensitivity reflection

Computing the capital charge is our main aim and this figure is given by:

Default Counterparty Capital Charge $=$ Exposure at default $\times$ Risk weight $\times 8 \%$

Where the SA-CCR EAD (Exposure at default) is our key figure, the risk weight is amended by Basel and the $8 \%$ reflects the pillar 1 obligation.

Computing the EAD would need to be held on each netting set level on a hedging set basis:

$$
\mathrm{EAD}=1.4 \times(\mathrm{RC}+\mathrm{PFE})
$$

where $\mathrm{RC}$ is the replacement cost and PFE the potential future exposure.

The concept of Equation (2) is referring to is the fact that the exposure to an instrument is the sum of its present value and the future potential values. The alpha factor is added as an insurance to cover the risk and the value of alpha is calibrated based on several internally generated models (seen in previous counterparty credit risk models), therefore this coefficient is kept constant all through the computation.

Hedging sets are defined as follows (details in pages $12-13$ of document [5]):

1) Interest rate: a hedging set is defined for one same currency further divided into maturities, long and short positions fully offset within maturity categories, across maturity categories partial offset is recognized

2) Foreign exchange: same currency pairs form same hedging sets, full offset is only permitted within a same pair

3) Credit derivatives and Equity derivatives: in these two categories each asset class forms a hedging set, full offset is permitted for a same entity (index or name) whereas partial offset between derivatives is applied when referring to different entities

4) Commodity derivatives: four hedging sets: energy, metals, agriculture and others. No offset among these categories. In a same hedging set, full offset for same commodity is permitted and partial offset is applied when handling different commodities.

The EAD formula changes in case the trade is margined or un-margined:

- If margined: $\mathrm{RC}$ represents the exposure if the counterparty defaults at time 
$t=0$ assuming the close-out does not take time and PFE is the change in value during the period between the default and the deployment of the collateral.

- If un-margined: $\mathrm{RC}$ is the present exposure and PFE is the potential increase in exposure over a one-year time horizon.

Replacement Cost

The RC is computed following two formulas: if the trade is margined or not (more details in [7], pp. 4-7.

For un-margined transactions:

$$
\mathrm{RC}=\max (0 ; V-C)
$$

where $V$ is the current market value of the derivatives and $C$ is the net haircut collateral held. Not having any margin, at time $t=0$ the replacement cost would depend on two possible outcomes: the instrument's value is in our favor or not. If the value of the instrument is higher than the collateral a default of the counterpart would result in a loss equal to $V$-C the value of the instrument minus the collateral value, if not, no loss is included: which explains the RC formulation in the un-margined case.

For margined transactions:

$$
\mathrm{RC}=\max (0 ; V-C ; \mathrm{TH}+\mathrm{MTA}-\mathrm{NICA})
$$

where $\mathrm{TH}$ is the positive threshold before the counterparty send the bank collateral, MTA is the minimum transfer amount applicable to the counterparty and NICA any collateral posted by the counterparty minus the one posted by the bank (net value). In this case the margin should be taken into account for the computation of the replacement cost: if the value of the instrument is inferior to the value of the collateral and the collateral posted by the bank is inferior to the one posted by the counterparty, the loss will be null. However, if any of the previously denoted figures is positive the replacement cost will be equal to it: if the posted collateral is more than the collateral of the counterparty or if the value of the instrument is higher than the total collateral the bank would have to cover these differences as a replacement cost.

Potential Future Exposure

$\mathrm{PFE}$ is given by:

$$
\mathrm{PFE}=\text { multiplier } \times \text { Add }- \text { On }{ }^{\text {Aggregate }}
$$

where the multiplier recognizes excess of collateral and negative mark-tomarket, and the add-ons are calculated for each asset class.

Computing the multiplier also detailed in [7], with a floor of $5 \%$ is computed as follows:

multiplier $=\min \left[1 ;\right.$ floor $+(1-$ floor $\left.) \times \exp \left(\frac{V-C}{2 \times(1-\text { floor }) \times \text { Add }- \text { on }^{\wedge}\{\text { aggregate }\}}\right)\right]$

The multiplier formula is built in a way to account for over-collaterization: The multiplier is normally at 1 however, if the bank chooses to over-collaterize the instrument they are holding, this multiplier will be inferior to 1 therefore 
giving the bank the advantage of their extra-safety arrangement.

And the add-on computation follows these steps:

1) Define the transaction primary risk factor.

2) Allocate it to an asset class: Interest rate (IR), Foreign exchange (FX), equity, credit or commodity

3) Compute the adjusted notional amount (for IR and credit duration is included).

4) Get the maturity factor (whether margined or not).

5) Multiply the supervisory delta by the adjusted notional (+ or -1 if long or short).

6) Multiply it by the given supervisory factor to reflect volatility.

7) Aggregate by hedging sets and asset-class level.

For more details on the specific computation of the Add-on for each asset class, please refer to the Basel document [7].

The SA-CCR add-on computation method is based on a set of assumptions in order to result in the previously cited formulas. These assumptions are the following:

- All trades are at the money $(\mathrm{MtM}=0)$.

- The banks neither hold nor post collateral.

- No cash flows are present before the one-year horizon.

- The evolution process of instruments follows a Brownian motion with zero drift and fixed volatility.

We note the important impact of the maturity factor on the computation: this latter depends on the portfolio: margined or not. If the portfolio is un-margined, the maturity factor (MF) applied is equal to:

$$
\mathrm{MF}^{\text {un-margined }}=\sqrt{\frac{\min (\text { 1year, Maturity })}{\text { 1year }}}
$$

However, if the portfolio is margined, MF depends on the remargining frequency. Basel amends a certain margin period of risk (MPOR) depending on the characteristics of the deals considered, this margin represents the closing time between the default of the counterparty and the margin payment. This concept is described in [5].

$$
\mathrm{MF}^{\text {margined }}=\frac{3}{2} \sqrt{\frac{\mathrm{MPOR}}{250}}
$$

where MPOR is defined by the frequency: for daily re-margining MPOR is equivalent to 10 . The general formula for an $N$ remargining per day frequency is:

$$
\text { MPOR }=10+N-1
$$

A daily re-margin is the most conservative, therefore we chose this frequency as a base of our application portfolios (in Section II.7).

However, we note that the $3 / 2$ multiplier maintained by Basel in order to approach the $\mathrm{EE}$ of a margined transactions to the one of an un-margined transaction for MPOR (reflected in [7]) is resulting in double accounting for the shock $(1.5 \times 1.4)$. 
Several comments were presented to try and remove this multiplier, such as the comments by Deutche bank, however, the multiplier remains present in the finalized version of the method.

A brief description of the SA-CCR mentioned above is shown in Figure 1.

\subsubsection{Internal Model Method (IMM)}

As the habit went, all internal models to be applied for banks should be accepted by the supervisor entitled for this bank (the national regulator). The bank in our case study is free to choose to model internally the EAD for the OTC derivatives. Having this in mind, Basel implemented in its third version [3] requirements that should be respected in order to get approval for the proposed internal model. Please note that due to several different approaches that could be considered in the internal model approach, in a consultative document, refer to [8], Basel proposed to floor the IMM capital charge to a certain percentage of the SA-CCR capital charge or better yet remove the IMM as an approved method to compute and report capital charges under the counterparty credit risk. However, all OTC instruments that were not included in the internal model or that could not assume approval to be globalized under the internal model should be treated through the standardized approach. We shall briefly describe the requirements for the EAD internal model but we note that these requirements are required on a permanent basis and continuous check-ups will be put in place in order to ensure the fully compliance to these rules all through the period of application of the chosen internal model.

In an attempt to make this more pleasant for readers and easier to discuss the conditions for the implementation of an internal model will be represented as

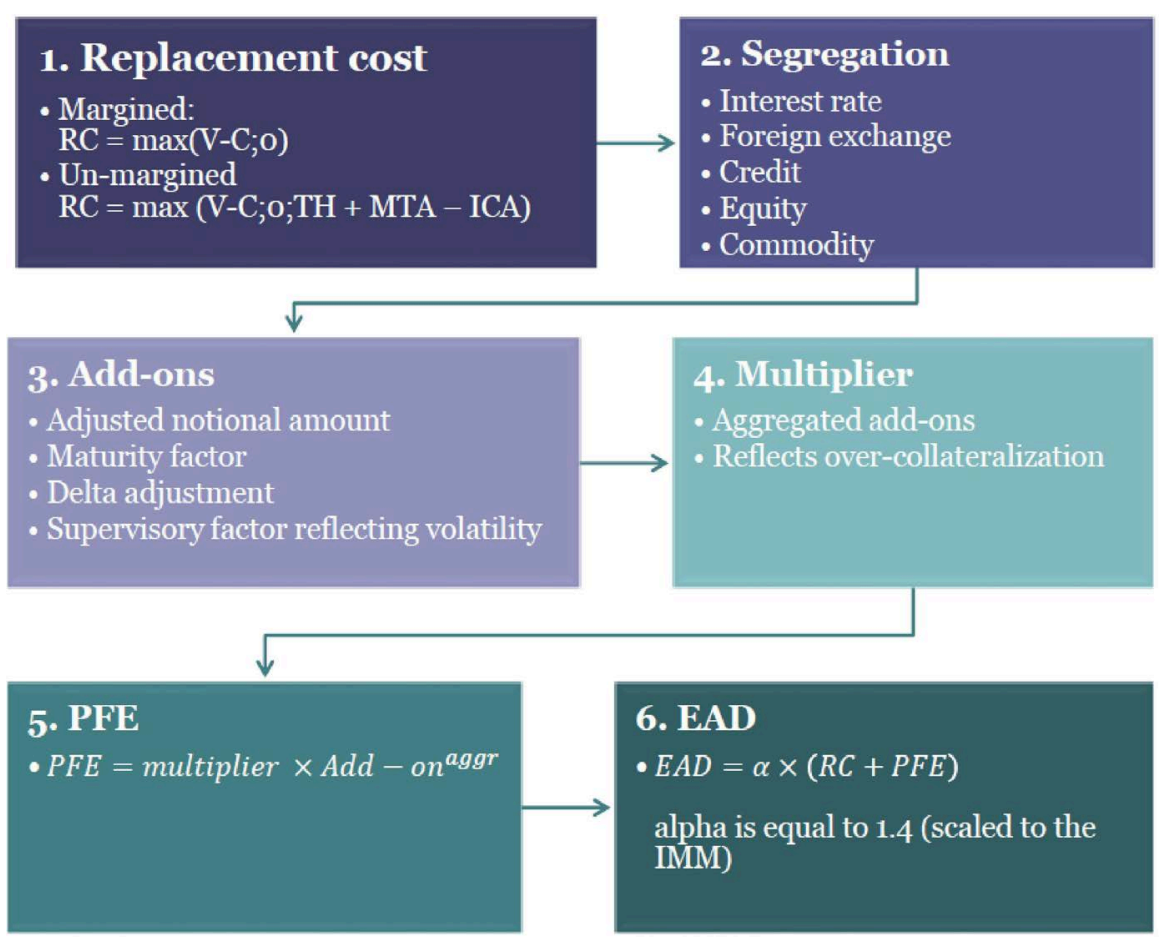

Figure 1. SA-CCR capital charge computation process. 
bullet points under each categories of requirements:

- The model should specify a forecasting distribution for changes in market value such as interest rate or foreign exchange rate.

- For margined counterparties, the model should also capture the future behavior of the collateral in question. Note that no particular form of model is required.

- Determining the default capital charge should be based on the greater computation using: once the current market data to calibrate the projection models and once a stressed calibration. In both cases the time frame should be three years and in the stressed conditions it should cover a stressed period in between (three years containing a stress among them).

- The computation will follow these given steps: the Exposure at Default (EAD) is the product of a previously calibrated (and negotiated) $\alpha$ factor and the Effective Expected Positive Exposure:

$$
\mathrm{EAD}=\alpha \times \mathrm{EEPE}
$$

Effective Expected Positive Exposure (EEPE) relies on internal model to predict counterparty exposures, typically simulating underlying market risk factors out to long horizons and revaluating counterparty exposures at future dates along the paths simulated, it is the weighted average of the Effective Expected Exposure (EEE).

$$
\mathrm{EEPE}=\sum_{k=1}^{\min (\text { 1year,maturity })} \mathrm{EEE}_{k} \times \Delta_{k}
$$

The EEE is the increasing function of the Expected Exposure (EE): this amends a more restrictive approach, once an exposure is hit the method does not permit a decrease in the exposure for future dates.

$$
\mathrm{EEE}_{k}=\max \left(\mathrm{EEE}_{k-1}, \mathrm{EE}_{k}\right)
$$

where $\Delta_{k}=t_{k}-t_{k-1}$ and $\mathrm{EE}_{k}$ being the average exposure at future date $k$ across possible future values of relevant market risk factors, and alpha set for 1.4 however a discussion permitting lower or greater alpha is possible (floored at 1.2). A more detailed look on these formulas is clearly presented in Pykhtin's article [9].

- The exposure should not only be limited for a given time horizon (ex: one year), it should cover the entire life of the portfolio (the OTC portfolio).

- Again for margined transactions, the internal model should account for the re-margining period, the mark-to-market valuation and a sets of floors set for the time horizons of deals.

- An independent management unit responsible for calculating and making calls for margin should be put in place.

- The bank must present: adequate documentation for the counterparty credit risk (CCR) management process, validation of the models, organizational approval, accurate reporting and reflective results.

- Before starting to use the model, a bank should calculate it for at least one year before implementation in order to have a set of observed outcomes of 
the chosen approach.

In the rest of this paper, we will choose for each case a given forecasting model in order to project the risk factors (interest rate and foreign exchange risk), calibrate it twice: once on a normal market and once in stress conditions, compute the EE and going up the formulas recover the EAD for the instrument in question in the both cases, the maximum EAD will be our IMM exposure at default. We note that the calibration, the re-evaluation and the models chosen for the IMM could change the capital charge amended by such approaches: the relative variability for IMM appears to be considerable between banks. Basel committee conducted an exercise in an attempt to compare the outcome of such models between banks and recommend a best practice for the IMM in the counterparty credit risk framework, this exercise can be found in [10].

\section{CVA Capital Charge Computation}

The CVA capital charge applies to all derivative transactions that are subject to the risk that a counterparty could default. However, the scope of application does not include derivatives cleared through a clearing (central) counterparty. It also encompasses securities financing transactions that are fair-valued by a bank for accounting purposes. CVA risk could be seen as a strong link between the counterparty and the market risk however it is by nature more complex than market risk on the trading book leading to different frameworks and choices about precise implementation. Reference [11] discusses this issue precisely. Recent Basel approaches amended two frameworks for the computation of this capital charge: The Fundamental Review of the Trading Book CVA framework (FRTB-CVA) and a Basic CVA approach (BA-CVA) as shown in Figure 2. Under the FRTB concept, banks are asked to compute the CVA sensitivities requiring the simulation of all exposures to a large panel of market risk factors. This procedure is very demanding, therefore some banks are enable to cover this calculation and therefore the basic approach presented in [12] is an option for these reasons. In February 2016, a QIS was sent by Basel to be calculated by banks on a voluntarily basis in order to measure the impact of these different approaches on the computation of the CVA capital charge, QIS found in [13].

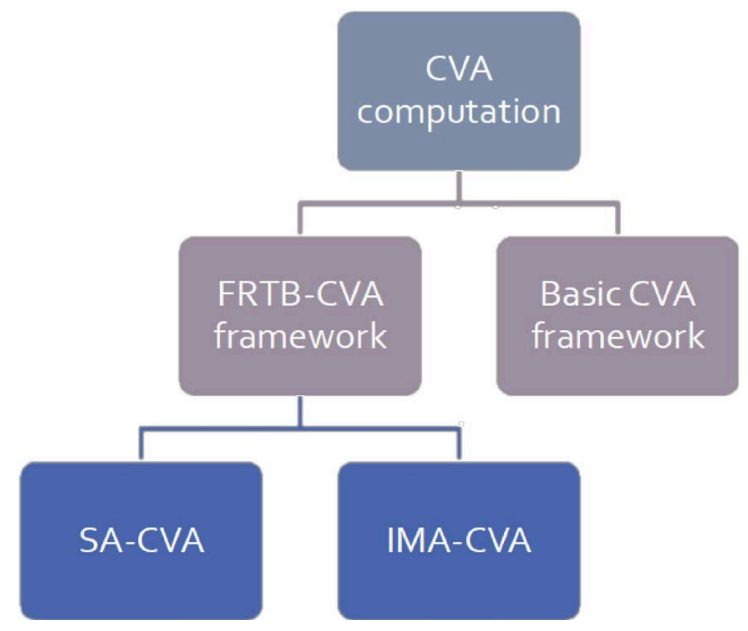

Figure 2. CVA capital charge computation methodologies. 


\subsection{Standardized CVA (SA-CVA, FRTB)}

Eligibility Criteria:

1) Ability to compute CVA sensitivities.

2) Methodology to approximate credit spreads for all counterparties (including illiquid ones).

3) Existence of an independent CVA risk management function.

Eligible hedges: Single-name instruments, proxy hedges and market risk hedges.

CVA calculation:

At least a monthly computation is entitled: For each counterparty (even if only one derivative is included).

The SA-CVA capital is the sum of delta and Vega risks. Each one of these categories are divided into sub-categories depending on the risk types as shown below in Figure 3. For each type, a certain methodology is used to bucket the assets and to compute their sensitivity.

For each risk type in both categories we compute (refer to BCBS (2015) p. 16-25):

- Sensitivity of the aggregate CVA

- Sensitivities of all eligible hedges

- Compute weighted sensitivities: Risk weights are given by Basel for each risk type.

- The net weighted sensitivity is the sum of the CVA weighted sensitivities and their hedges.

- Within each bucket, weighted sensitivities are aggregated to form the bucket's cc.

- Across buckets computation results in the total capital (detailed description in [14]).

\subsection{Advanced Internal Model Method IMM-CVA FRTB}

The use of this method is conditioned upon approval of supervisor's authority. Briefly citing the conditions: regular back testing, a trial period, expected shortfall approach, 97.5 confidence level, cover delta and vega risks, stressed period

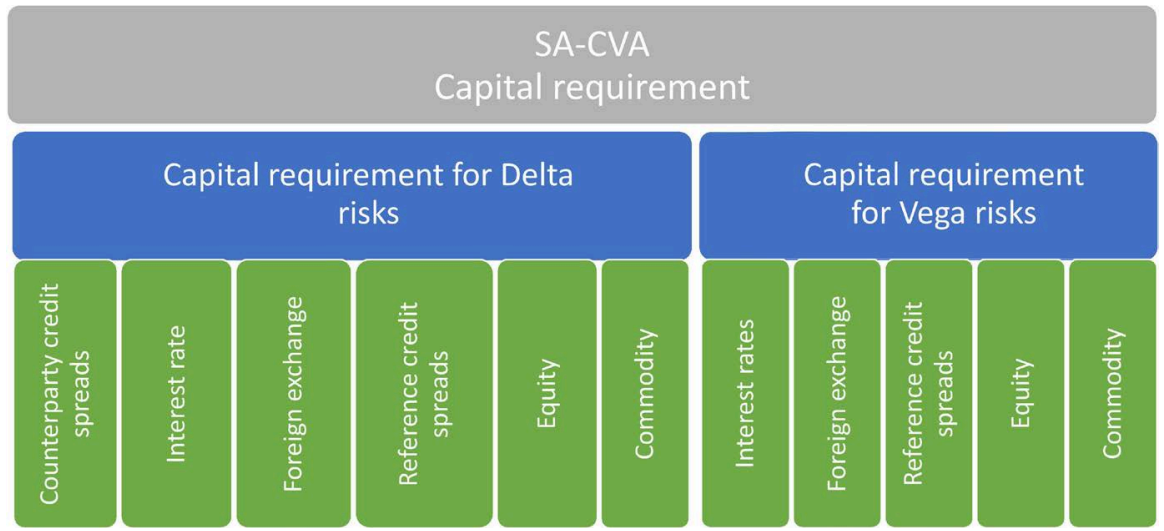

Figure 3. Standardized CVA categorization. 
calibration. The methodology is to compute internally the CVA expected shortfall (netted assumptions) and then to compute this figure for each asset types: interest rate, FX, credit spread, equity and commodities in order to sum all of them and get the gross expected shortfall. The average of the two expected shortfalls is considered and a regressive formula is put in place in order to compute the required capital charge.

\subsection{Basic CVA (BA-CVA)}

The basic CVA approach is for banks that are not able to compute the CVA sensitivity or does not have the approval of their authorities to use the FRTB-CVA introduced in [12]. However, this approach is known to be very demanding and very conservative in terms of risk weights placed by Basel.

Before detailing the computation of the capital charge it is important to cite very briefly the eligible hedges in this framework: single-name CDS that references the counterparty directly, or references an entity legally attached to it or references an entity that belongs to the same sector and region of this counterparty; single-name contingent CDS and index CDS.

The basic CVA capital charge is given by the sum of the spread capital $\left(K_{\text {spread }}\right)$ and the expected exposure capital $\left(K_{\mathrm{EE}}\right)$ :

$$
K_{\mathrm{CVA}}=K_{\text {spread }}+K_{\mathrm{EE}}
$$

The formulation of the capital charge is intuitive because the CVA is the risk a bank is facing in case of a fluctuation in the credit quality of the counterparty therefore the two main factors are the credit quality represented by $K_{\text {spread }}$ and the expected exposure amount parallel to this change: $K_{\text {exposure }}$. Differentiation in computation apply if the portfolio is hedged or not (hedging the CVA risk or not). Considering that no hedging strategies were put in place for hedging this kind of risk, which is the case for the majority of small and medium banks having the CVA as a relatively new capital charge computation, we will apply the following formula:

$$
K_{\text {spread }}^{\text {unhedged }}=\sqrt{\left(\rho \sum_{c} S_{c}\right)^{2}+\left(1-\rho^{2}\right) \sum_{c} S_{c}^{2}}
$$

where $S_{c}$ is the supervisory expected shortfall of CVA of counterparty $c$ and $\rho$ is the supervisory correlation between the credit spread of a counterparty and the systematic factor set to $\rho=50 \%$.

The second term of Equation (8) is given by a simple scaling of $K_{\text {spread }}$ :

$$
K_{\mathrm{EE}}=0.5 \times K_{\text {spread }}^{\text {unhedged }}
$$

Therefore the computation is held in the $S_{c}$ term:

$$
S_{c}=\frac{R W_{b(c)}}{\alpha} \sum_{N S \in c} M_{N S} \mathrm{EAD}_{N S}
$$

$\alpha$ is non-other than the $\alpha=1.4$ discussed earlier, EAD are the EAD internally computed earlier on a netting set level, $M_{N S}$ is the effective maturity of the 
netting set and $R W_{b(c)}$ is the risk weight set by Basel for the risk bucket $b_{(c)}$. The different weights are shown in Basel paper [12].

\section{Application}

\subsection{Data Used}

In the following, we chose to work on three different portfolios composed each time of one unique instrument: an interest rate swap, an FX forward and a FX plain vanilla call respectively. No netting is considered and no collateral nor margin agreements are added in this first step.

In each scenario, we computed the capital charge of the portfolio for different maturities of the instrument (going from 6 months to 5 years) in order to see the progression in time of the capital charge (in standardized or internal approaches).

The choice was made due to different causes:

- To cover several asset classes.

- To study differences between instruments with or without optionality.

- The interest rate segment accounts for the majority of OTC derivatives activity and represented around $80 \%$ of the global OTC derivatives market by June 2015.

- Foreign exchange derivatives make up the second largest segment of the global OTC derivatives market with around 13\% of the market by mid-2015, and FX forwards make up half of the notional amount outstanding in this asset class.

We detail the three considered portfolio in this section:

IR swaps: We start by considering a portfolio containing one interest rate swap denoted in USD: one floating leg and one fixed leg of 100 USD as notional with semi-annual payments. The fixed coupon rate is defined in a way for the present MtM of the swap to be null. We will consider different versions of this portfolio by changing the maturity of the swap: from a 6-month interest rate swap to a five-year swap.

FX forward: We consider a portfolio containing one FX forward USD-EUR. The forward rate is computed in such way that the present MtM is null. As we did earlier, we will consider different cases of this portfolio by changing the maturity of the forward: from a 6 month FX forward to a five year FX forward.

Plain vanilla option: We consider a portfolio with a single FX plain vanilla call (USD/EUR), long position, with maturities going from 6 months up till 5 years, a notional of 100 EUR, a strike price of 1.4 (the actual spot is 1.0963). The $\mathrm{MtM}$ of the call is not null and it is priced using the Black and Scholes formula with the market implied volatility.

The data used are fetched from Bloomberg platform: (see Appendix 2 for the plots)

- USD swap curve, EURO swap curve and the FX spot rate (USD-EUR).

- For each swap curve the observed tenors are 1 month up till 50 years.

- Daily frequency. 
- Historical observed dates: since end of April 2004 until end of April 2007.

- Swap curve number of observations: 1536 per tenor (112,128 observations).

- FX curve: 1565 observations.

\subsection{Capital Charge Computation}

\subsubsection{Default Capital Charge}

Considering a risk weight of $100 \%$ and the pillar 1 factor as $8 \%$, by multiplying the obtained EAD by these two components we would be able to compute the capital charge to cover the counterparty credit default risk (as seen in Equation (1)). Therefore, in the following we will just demonstrate the EAD results, final computation will be added in the next section.

\subsubsection{SA-CCR}

\section{IR swaps}

Explaining step by step the computation will result in the following:

$$
\mathrm{EAD}=1.4 \times(\mathrm{RC}+\mathrm{PFE})
$$

In an attempt to replicate the SA-CCR assumptions, we considered interest rate swaps with an initial $R C$ equal to 0 (we compute the fixed coupons in a way that is equivalent to the floating leg cash flows). As for the $P F E$, it is the product of the multiplier and a given Add-on. The multiplier is here to add the characteristics neglected in the add-on assumption: referring to the assumptions of the SA-CCR add-on computation formulas p.16, no collateral is considered, therefore the multiplier is added to the formulas in order to incorporate the collaterization effect. Moreover, the multiplier is floored at $5 \%$ in order to always account for the PFE even when we have a very important collaterization. In our case, no collateral is recognized therefore the multiplier is one.

$$
\text { PFE }=\text { multiplier } \times \text { Add }- \text { on } \quad \text { multiplier }=1
$$

The Add-on depends on the asset type, for the interest rate the Add-on is computed as the product of a maturity factor, a supervisory factor, an adjusted notional and a directional delta. The adjusted notional of the IR bucket is equal to the notional amount multiplied by the duration of the instrument for a given rate of $5 \%$. Basel justifies the supervisory factor of $0.5 \%$ as the one-year volatility of the swap rate.

$$
\begin{aligned}
& \text { Add }- \text { on }=\text { Supervisory factor for } I R \times \text { Effective Notional } \\
& \text { Supervisory factor }=0.50 \% \\
& \text { Effective Notional }=\delta_{i} \times d_{i} \times M F_{i} \\
& \delta_{i}=+1, d_{i}=\text { Notional } \times S D_{i} \\
& S D_{i}=\frac{\exp \left(-0.05 * S_{i}\right)-\exp \left(-0.05 * E_{i}\right)}{0.05} \\
& M F_{i}=\sqrt{\frac{\min (\text { lyear, Maturity })}{\text { lyear }}}
\end{aligned}
$$

where $S_{i}$ is equal to 0 in our case and $E_{i}$ is equal to the maturity for each case and $M F_{i}$ is defined as if in order to scale down the supervisory factor (meaning 
Table 1. IR swap SA-CCR results.

\begin{tabular}{ccccccccccc}
\hline Maturity (years) & 0.5 & 1 & 1.5 & 2 & 2.5 & 3 & 3.5 & 4 & 4.5 & 5 \\
EAD (\% of notional) & 0.24 & 0.68 & 1.01 & 1.33 & 1.65 & 1.95 & 2.25 & 2.54 & 2.82 & 3.10 \\
\hline
\end{tabular}

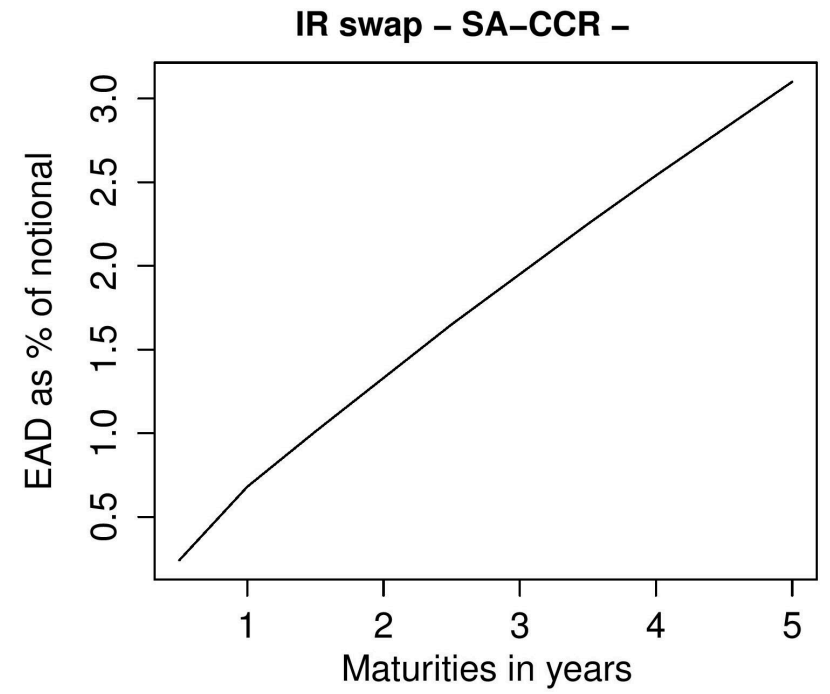

Figure 4. Interest rate swap EAD under SA-CCR.

to reduce the volatility for instruments of less than one year). Results for the EAD of this instrument are shown in Table 1 and Figure 4.

Not having any optionality, the IR swap only "variable" is the effective notional. This latter is computed as a continuous version of a bond duration with a maturity equivalent to the maturity of the interest rate swap (details can be found in Appendix 1). The duration being an increasing function of the maturity, the curve is expected to have an increasing trend. An additional supervisory factor is multiplied in order to "evaluate" the risk of such asset class. Note that the supervisory factor for the interest rate risk is the lowest for only 0.5

\section{FX forwards}

The $R C$ and multiplier reasoning are the same as the one previously explained in the IR case:

$$
\begin{gathered}
\mathrm{EAD}=1.4 \times(\mathrm{RC}+\mathrm{PFE}) \\
\mathrm{RC}=0 \\
\mathrm{PFE}=\text { multiplier } \times \text { Add }- \text { on } \\
\text { multiplier }=1
\end{gathered}
$$

As for the Add-on, the difference in the FX type is: the effective notional (representing the one-year volatility) is independent of the maturity therefore the effective notional is simply the notional amount.

$$
\begin{gathered}
\text { Add }- \text { on }=\text { Supervisory factor for FX } \times \text { Effective Notional } \\
\text { Supervisory factor }=4.0 \% \\
\text { Effective Notional }=\delta_{i} \times d_{i} \times M F_{i} \\
\qquad \delta_{i}=+1
\end{gathered}
$$




$$
d_{i}=\text { Notional and } M F_{i}=\sqrt{\frac{\min (\text { lyear, Maturity })}{\text { lyear }}}
$$

Not having any optionality, nor implying the maturity into computation the FX forward EAD curve seen in Figure 5 is divided into two parts: before the one-year maturity and after one year. The computation is rather simple multiplying the notional amount, supervisory factor and capped maturity presented in Table 2. Note that the supervisory factor for the foreign exchange bucket is much more important than the interest rate amended factor (by 8 times) and it is equal to $4.0 \%$ justified by the regulator as the first year instrument volatility.

Plain vanilla call

$$
\begin{gathered}
\mathrm{EAD}=1.4 \times(\mathrm{RC}+\mathrm{PFE}) \\
\mathrm{RC}=0 \\
\mathrm{PFE}=\text { multiplier } \times \text { Add }- \text { on } \quad \text { multiplier }=1 \\
\text { Add }- \text { on }=\text { Supervisory factor for } \mathrm{FX} \times \text { Effective Notional }
\end{gathered}
$$

Supervisory factor $=4.0 \%$

Effective Notional $=\delta_{i} \times d_{i} \times M F_{i}$

$$
\delta_{i}=+\Phi\left(\frac{\ln \ln \left(\frac{P_{i}}{K_{i}}\right)+0.5 \times \sigma_{i}^{2} \times T_{i}}{\sigma_{i} \times \sqrt{T_{i}}}\right)
$$

$$
P_{i}=\text { underlying spot }=1.0693
$$

Table 2. FX forward SA-CCR results.

\begin{tabular}{ccccccccccc}
\hline Maturity (years) & 0.5 & 1 & 1.5 & 2 & 2.5 & 3 & 3.5 & 4 & 4.5 & 5 \\
EAD (\% of notional) & 3.96 & 5.60 & 5.60 & 5.60 & 5.60 & 5.60 & 5.60 & 5.60 & 5.60 & 5.60 \\
\hline
\end{tabular}

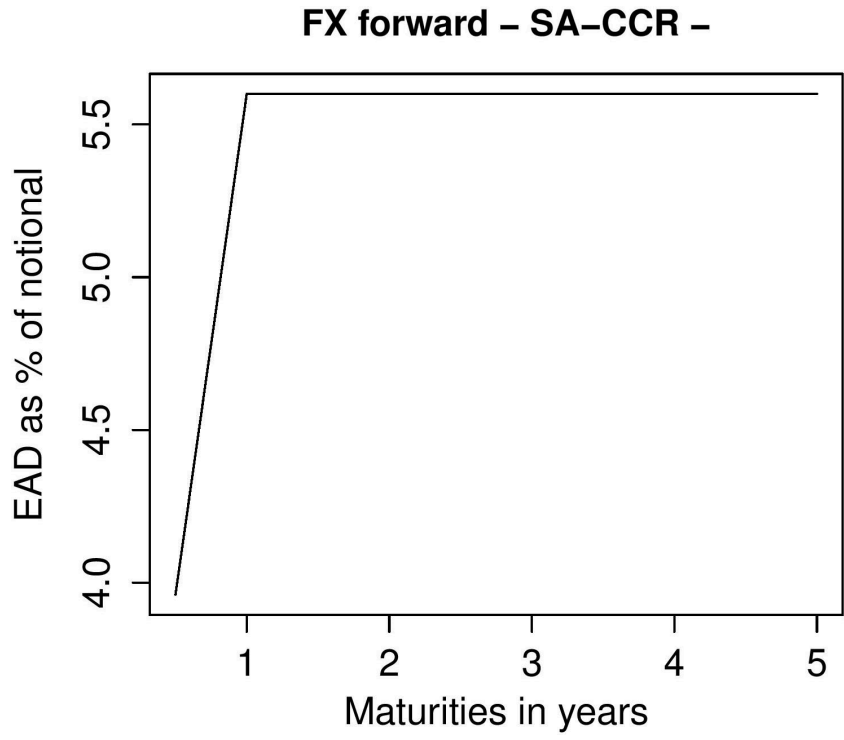

Figure 5. FX forward EAD under SA-CCR. 


$$
\begin{gathered}
K_{i}=\text { strike }=1.3 \\
\sigma_{i}=15 \% \text { supervisory volatility } \\
d_{i}=\text { Notional }=100 \\
T_{i}=\text { maturity } \\
M F_{i}=\sqrt{\frac{\min (\text { lyear, Maturity })}{\text { 1year }}}
\end{gathered}
$$

This is another example in the FX bucket therefore the supervisory factor is $4.0 \%$. On the first hand, we note that in this case the replacement cost is not null: it is computed as the price of the option (black and Scholes). On another hand, due to the optionality of this instrument an additional factor is added: the delta. When handling instruments with no optionality, the delta factor is equal to 1 or -1 in order to reflect if we are short or long on the transactions. However, in this case the delta is computed as the normal cumulative function of a given figure. This is the risk-adjusted probability of exercise derived from the Black and Scholes formula in [15]. In the delta computation, a $15 \%$ volatility is amended by the regulator. Results are reflected in Table 3 and Figure 6.

Table 3. FX plain vanilla call SA-CCR results.

\begin{tabular}{ccccccccccc}
\hline Maturity (years) & 0.5 & 1 & 1.5 & 2 & 2.5 & 3 & 3.5 & 4 & 4.5 & 5 \\
EAD (\% of notional) & 0.28 & 1.12 & 1.84 & 2.47 & 3.04 & 3.52 & 3.97 & 4.37 & 4.75 & 5.09 \\
\hline
\end{tabular}

\section{FX plain vanilla call -SA-CCR-}

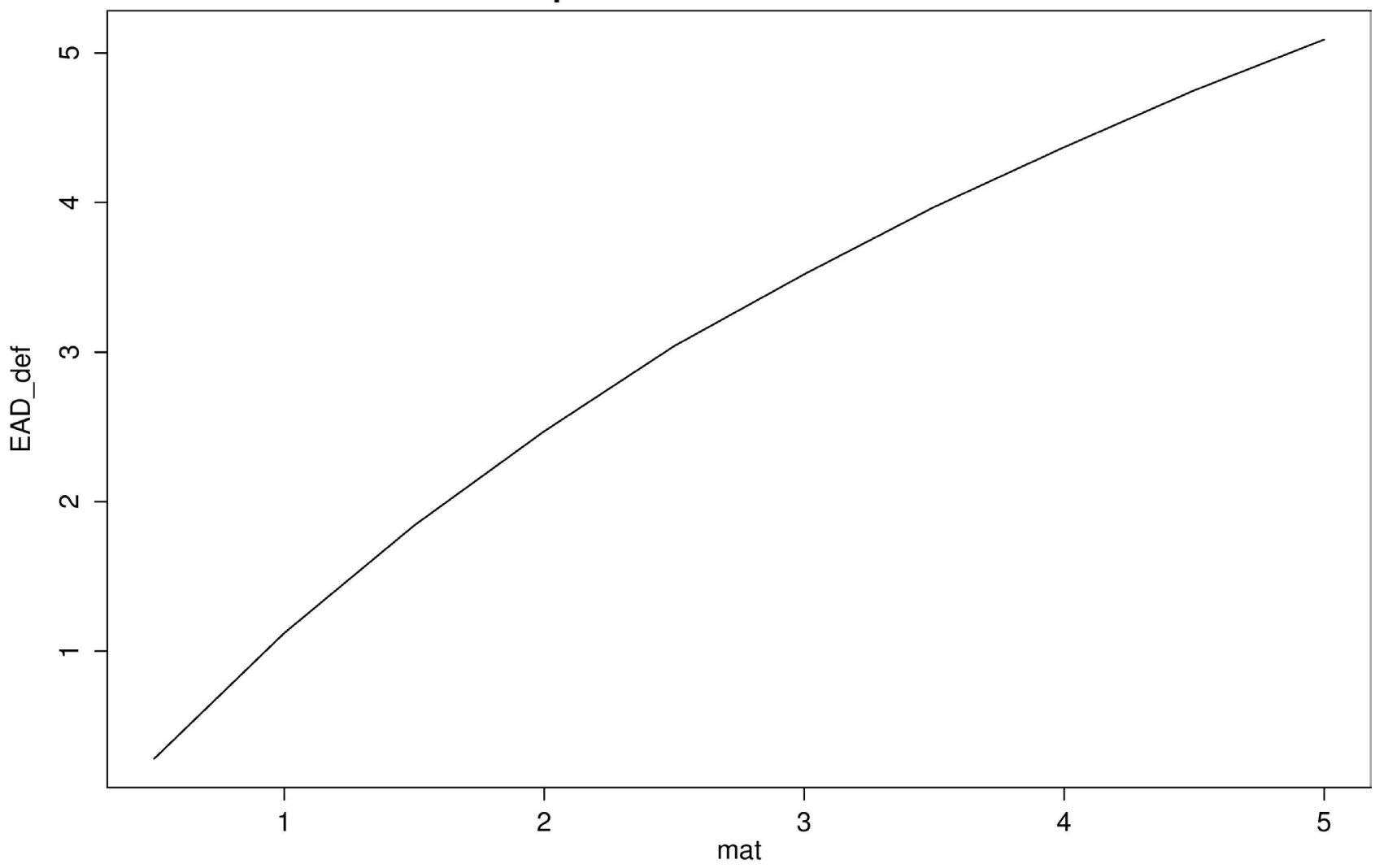

Figure 6. FX plain vanilla call EAD under SA-CCR. 


\section{Internal Model Method}

We build our models reflecting historical observations and incorporate expert opinions along with forecasting visions respecting in parallel the recommended practices amended by Basel such as the daily steps, the numerous simulations... Detailed explanation on both models: interest rate and FX rates are found here below.

\section{Interest rate models}

\section{USD interest rate model}

After the sub-prime crisis and European debt period, we are in a very low interest rate environment (even negative) and all expectations vote for an increase in the rates (interest rates or FX rates).

The Federal Open Market Committee (FOMC) forecasting schema is one of the most used and trusted interest rates projections because it is based on experts' opinion trying to reflect and anticipate the market behavior. These projections found in [16] and represented in Figure 7, are those of Federal Reserve Board members and Federal Reserve Bank presidents.

The data we are using ends at $t=0,27$ December 2015, therefore we chose the forecasting of the FOMC in order to get an idea of the expert opinion projection of the market. FOMC presents several projections however we represent the most stressed anticipations starting December 2015 here-below:

We can notice that the market tendency is to go up: $1.5 \%$ after one year, $2.3 \%$ after two years, $3.15 \%$ after three years and a $3.5 \%$ rate on the long run. Therefore, we need to calibrate our historical model on an upward trend period. We chose to calibrate our internal approach to the period of rates increase of 2004-2007 and chose the best fit calibration: calibrating the models to a historical period, projecting today's yield curve based on these projections and com-

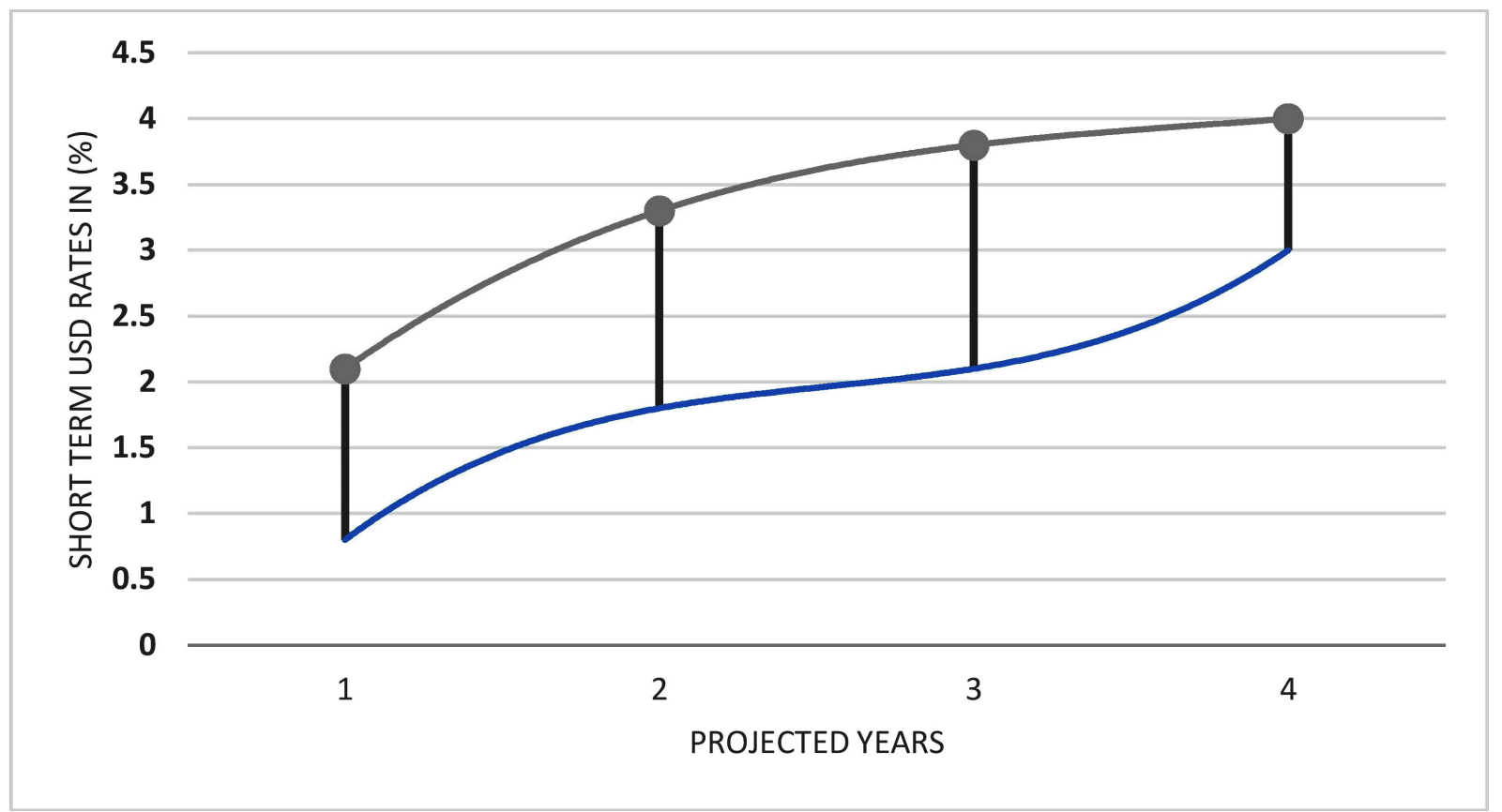

Figure 7. FOMC USD short rates most stressed projections. 


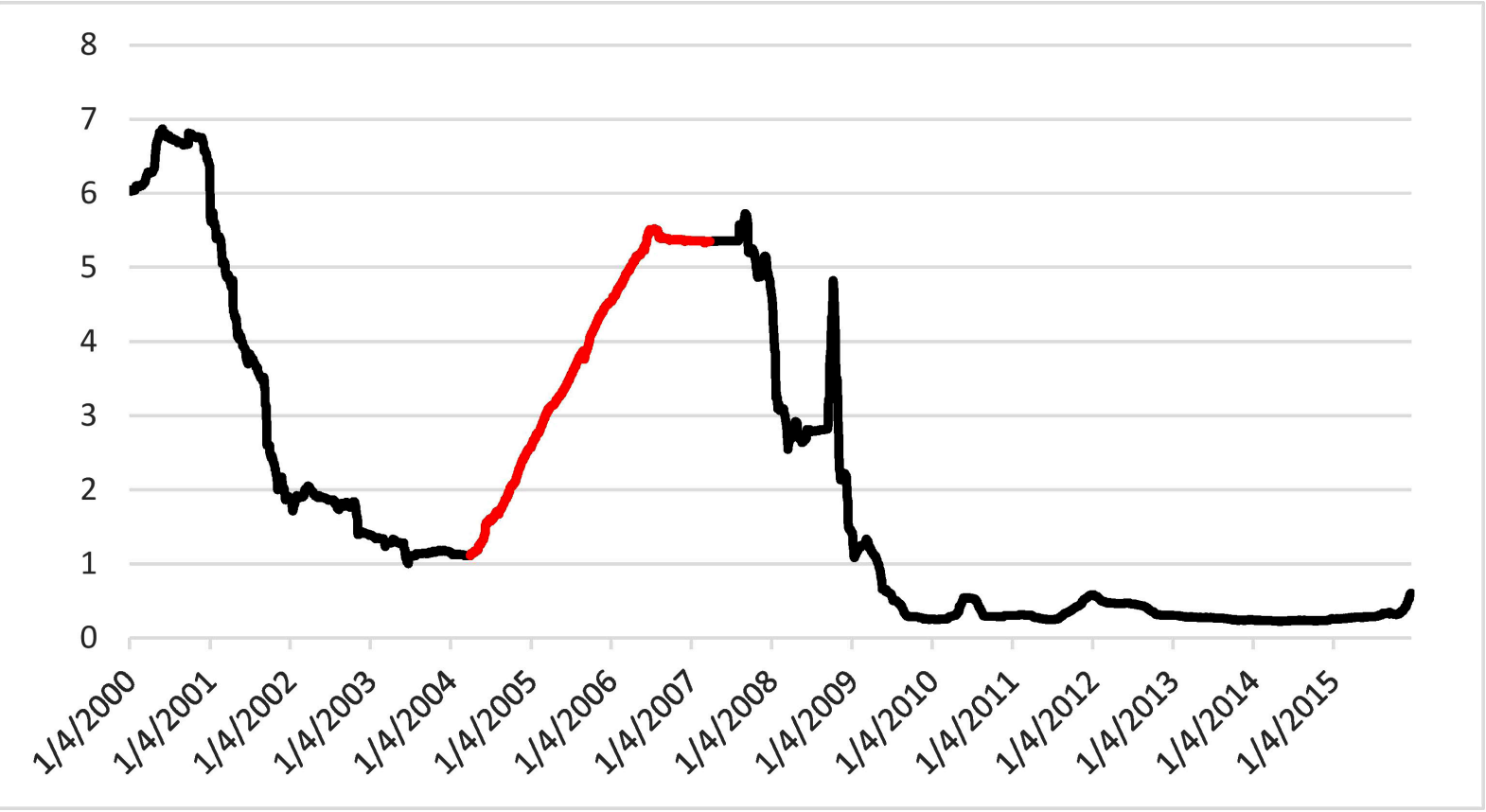

Figure 8. Calibration period on the USD short rates.

paring our IMM yields with the FOMC most stressed rates in order to choose the best fit.

Doing so, the stressed period chosen was: 30 April 2004 till 30 April 2007 to calibrate our IMM, represented in Figure 8. As an interest rate model we chose to use the well-known Vasicek approach.

The chosen model that we found adequately representative of the market is the Vasicek model: This is an easy model, incorporating the drift and implemented in most of the banking solutions. Choosing the simplest model was set to simplify the most this interpretation. However, Vasicek is a very sensitive model and differs amply with its calibrations however, following the previously cited technique we were able to choose a calibration that fits the market today following three main steps. These three steps should be repeated once on the stressed market calibration and once again on the current market conditions, comparing the EAD results we chose the maximum between both calibrations as our IMM given EAD. The results are as follow:

- Step 1: Calibrate Vasicek models on the historical stressed (resp. actual) period and get the parameters as per Table 4; the calibration is based on [17].

- Step 2: In order to fit the yield curves, we only change the speed of adjustment $k$ in order to find the new speed at which our yields curve today would converge to the calibration conditions. Keeping all other parameters constant reflects the market and investors' behavior in the calibration times (notably in times of stress). However, by changing the speed of adjustment in order to fit the actual yield curve, we change the long run of our model, results are represented in Table 5.

- Step 3: Based on these curves we evaluate our instruments and discount the cash flows in order to compute the required capital charges and EAD: The 
maximum EAD is chosen as the IMM EAD.

\section{EUR interest rate model}

The same approach is used for the EUR interest rate model: Vasicek is calibrated on the same historical upwards choc then re-parameterized to fit today's yields. The calibration and trend of the EUR curve is shown below in Figure 9.

\section{Foreign Exchange model}

As for FX models, we use GARCH $(1,1)$ model to reflect the volatility of these rates: it is calibrated at the same time-frame and projected. We note that the projection results of our model are in sync with Bloomberg's forecasting scenarios (most stressed) for the upcoming years. As for the pricing models for the FX options we chose to price based on the well-known Black and Scholes formula incorporating the volatility deducted from the GARCH $(1,1)$ model. On a final note, in the FX instruments both interest rates and FX models are used. In order to remain homogeneous between models the same random variable is used in all

Table 4. Vasicek parameters for USD short rates.

\begin{tabular}{ccccccc}
\hline & $k$ & $\theta$ & $\sigma$ & $\lambda$ & $\theta^{*}$ & \multicolumn{1}{c}{${ }^{*}$} \\
\hline Stressed & 0.4050 & 0.07299 & 0.0015429 & 5.1172 & 0.053500 & 0.0535 \\
Actual & 0.00347 & 0.09629 & 0.0005517 & -0.44712 & 0.006031 & 0.00603 \\
\hline
\end{tabular}

Table 5. Vasicek parameters for USD yields generation.

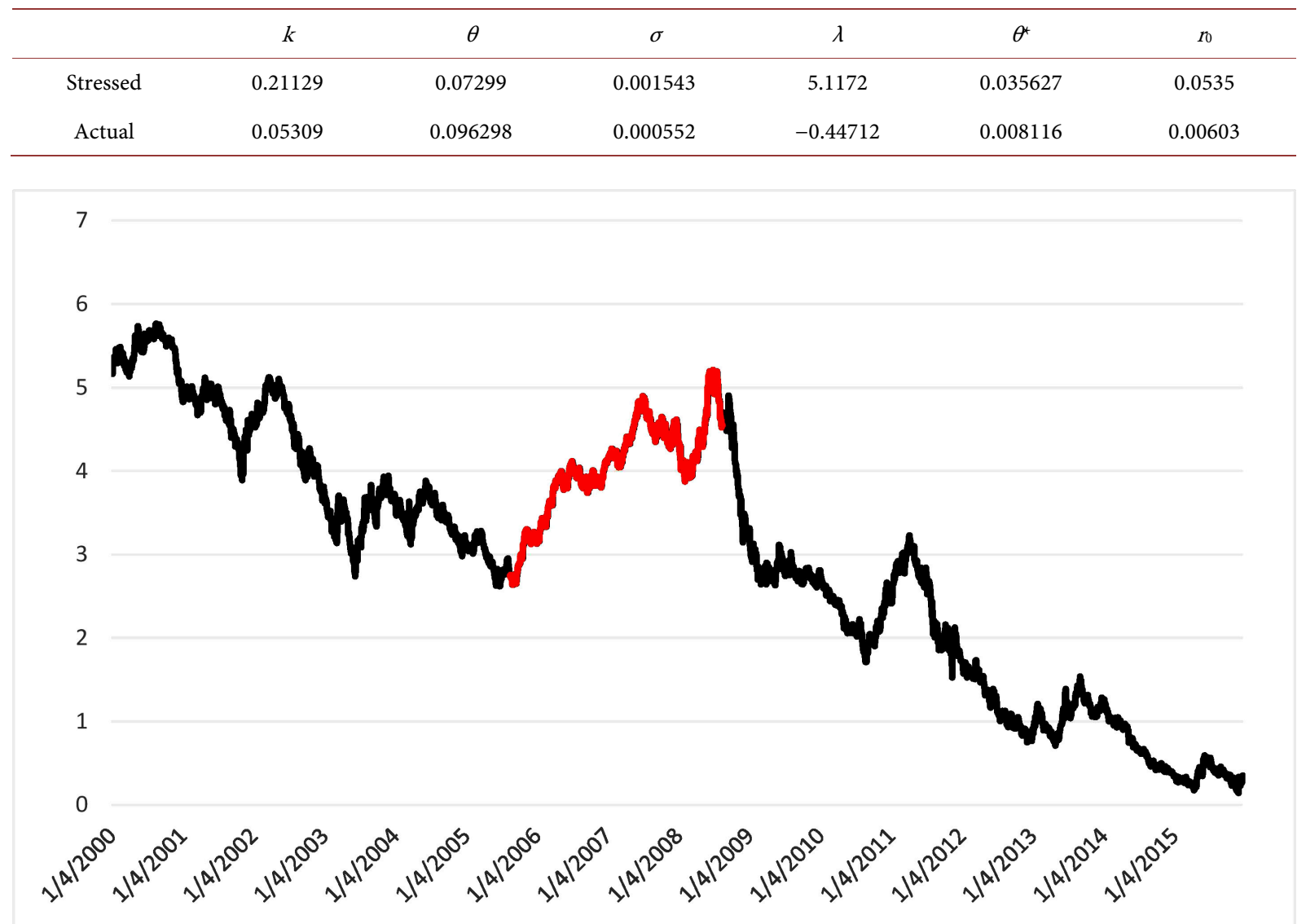

Figure 9. Calibration period on the EUR short rates. 
models used for one given scenario.

\section{PORTFOLIO 1: Interest rate swaps}

The EAD value will be deduced following formulas (3), (4) and (5) of Section II. As previously detailed, we started to model the IR swap curve for the USD on normal conditions and on stressed market conditions in order to get the EAD as the maximum of these two sets of calibrations (see Appendix $\mathbf{3}$ for a detailed presentation of this approach and of the parameters estimations). We have modeled the behavior of the interest rate swap based on this model, we have projected in the future the EE, then the EEE. Afterwards, with a $\Delta=\frac{1}{250}$ (daily basis) we have computed the EEPE and the $\alpha=1.4$ resulted in obtaining the EAD figure. As mentioned above, this was done twice and the resulting EAD is the maximum exposure for both sets of conditions.

We highlight the fact that in our models, an increase in rates is amended therefore among counterparties there will always be one party with a higher exposure than another whereas in Basel the standardized approach asks for the same capital charge for both positions. In our IMM, the maximum exposure of both long and short positions is asked from both counterparties in order not to perturb the market equilibrium. Trying to better clarify this previous assumption: Let us consider two counterparties with the same risk profile, if these two parties enter an interest rate swap we will have one institution paying fixed and receiving floating and the other one doing exactly the opposite.

Trying to reflect the exposure of each, one party will be paying almost null capital charge whereas the other will be paying an important amount.

To keep the market equilibrium (not to add a risk premium on the instrument price) and not to manipulate with the market, both counterparties are asked to place the same capital charge. This defined capital charge, in order to be the most restrictive is going to be the maximum of the short and long exposures.

The application of this process is shown in Table 6 (in \% of notional), comparing it to the previously computed standardized approach EAD and following different maturities in years:

Figure 10 shows that following a Vasicek model we can resemble the standardized approach behavior on the maturities going from 0.5 year up to almost 5 years which is the most frequent maturities encountered in such instruments for our portfolios. However, we can notice that the IMM gives slightly lower EAD for all of these maturities. The IMM-EAD is almost equivalent to $80 \%$ of the SA-CCR-IMM.

\section{PORTFOLIO 2: FX forwards}

Again following the EAD computation technique explained in the IMM section we shall apply our own chosen models to compute the EE of an FX forward (USD-EUR). The methodologies used will need a part to project the yield curve and another part to project the FX rate.

Choosing the Vasicek model for the yield curves (both USD and EUR) is followed to keep consistency with the IR swap. However, for the FX rate a GARCH 
Table 6. IR interest rate swap internal model results.

\begin{tabular}{ccccccccccc}
\hline Maturity & 0.5 & 1 & 1.5 & 2 & 2.5 & 3 & 3.5 & 4 & 4.5 & 5 \\
SA-CCR & 0.244 & 0.68 & 1.01 & 1.33 & 1.64 & 1.95 & 2.25 & 2.54 & 2.82 & 3.09 \\
IMM & 0.098 & 0.43 & 0.82 & 1.08 & 1.36 & 1.58 & 1.84 & 2.05 & 2.30 & 2.51 \\
\hline
\end{tabular}

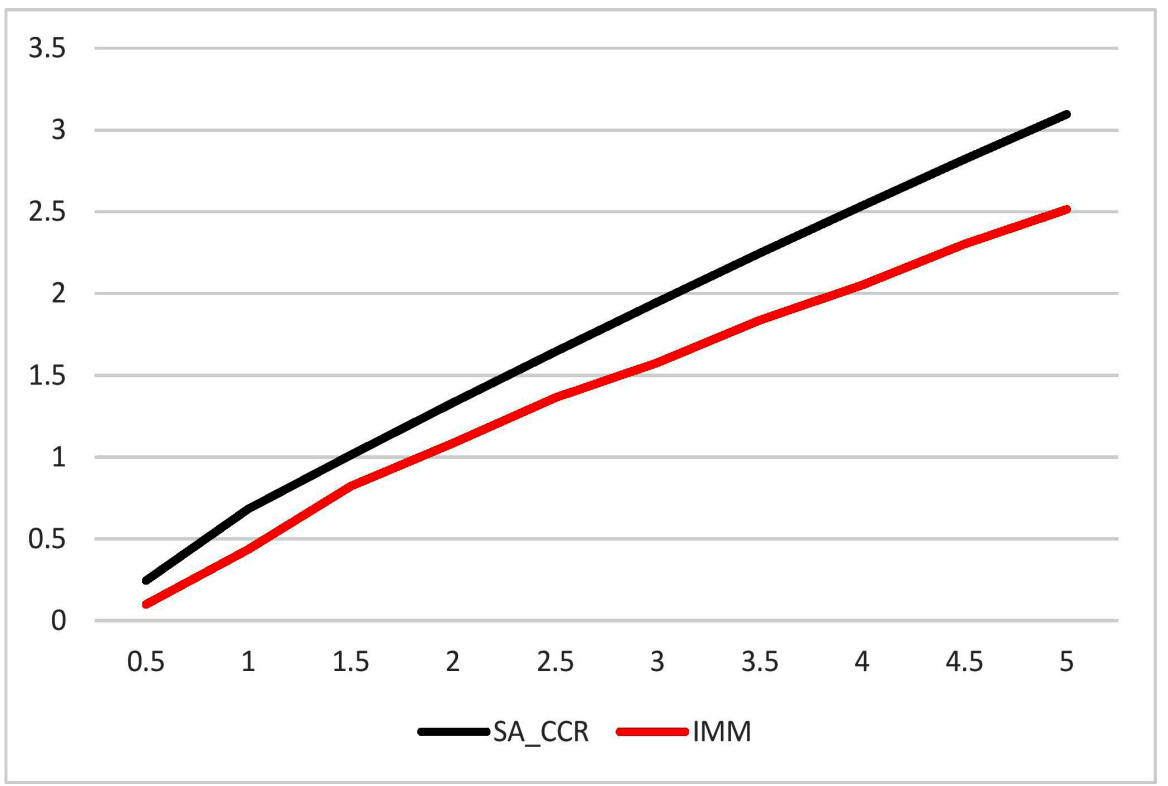

Figure 10. Interest rate swap EAD under the IMM.

$(1,1)$ was calibrated to the model and the rates were projected following this approach (refer to Appendix 4 for the GARCH model details).

Again with a daily step and an alpha factor of 1.4 the results, Table 7 and Figure 11 reflect the EAD as a percentage of the notional amount of the forward:

We had previously seen the two different stages of the standardized approach EAD following the maturity of the instrument (before and after one year). Here, the internal model will also differ between these two stages computing the EPE as an average on the first year.

We can notice that the behavior of the internal model resembles the one described by the SA-CCR computation however the IMM is less demanding than the SA-CCR when using models based on one factor Vasicek and Garch $(1,1)$. Both approaches converge to a 5.6\% EAD to notional amount. However, on a certain time range the IMM "explodes" due to the time limits of the GARCH approach.

\section{PORTFOLIO 3: FX plain vanilla call}

The third portfolio contains a plain vanilla FX call option: measuring the EAD will demand a forecast for two risk factors: the FX rate and the interest rate (EUR and USD). Based on the same logic as previous applications, we applied a Vasicek model for the interest rates and a Garch approach for the forecast of the foreign exchange rate. Adding to that a Black-Scholes traditional pricing formulation was used based on the GARCH-computed volatilities at each time $t$. 
Table 7. FX forward EAD internal model EAD results.

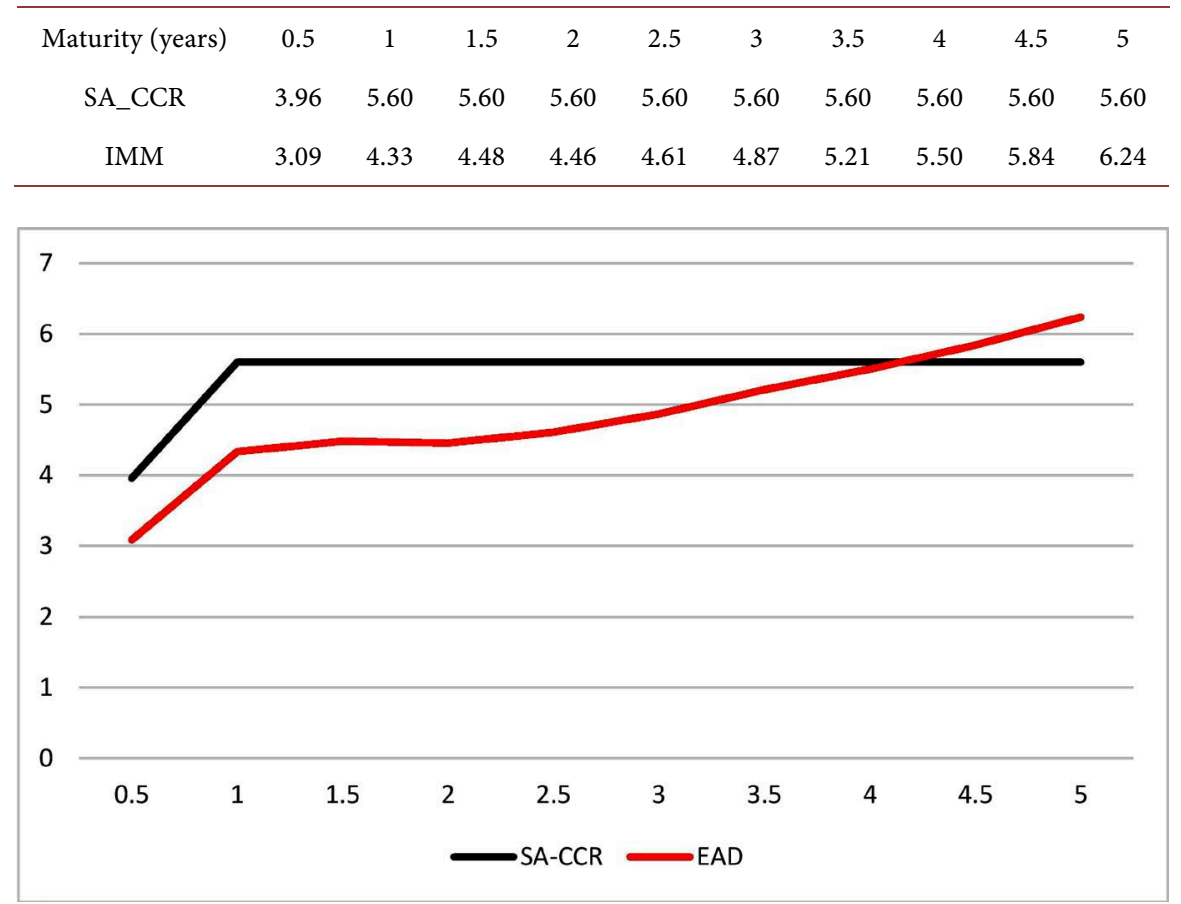

Figure 11. FX forward EAD under the IMM.

Table 8. FX options EAD internal model EAD results.

\begin{tabular}{ccccccccccc}
\hline Maturity (years) & 0.5 & 1 & 1.5 & 2 & 2.5 & 3 & 3.5 & 4 & 4.5 & 5 \\
SA-CCR & 0.28 & 1.12 & 1.84 & 2.47 & 3.04 & 3.52 & 3.97 & 4.37 & 4.75 & 5.09 \\
IMM & 0.31 & 1.13 & 1.65 & 2.10 & 2.48 & 2.84 & 3.15 & 3.43 & 3.69 & 3.94 \\
\hline
\end{tabular}

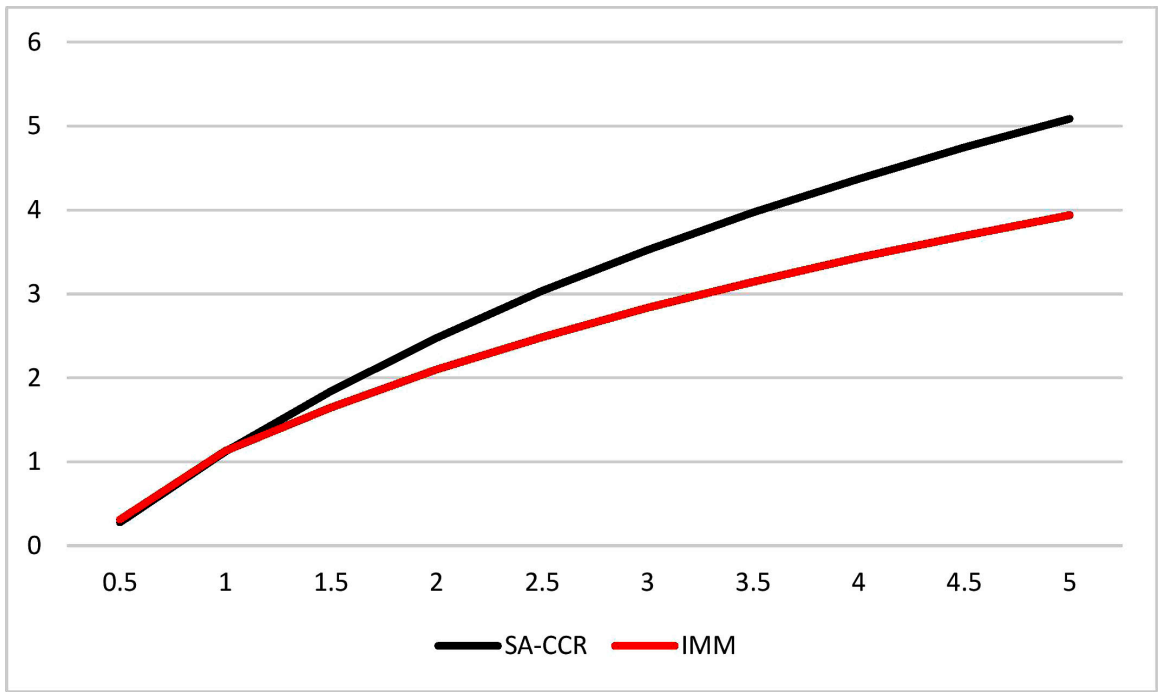

Figure 12. FX plain vanilla call EAD under the IMM.

Computing the EE then following the IMM process, we obtain in Table 8 and Figure 12 the EAD as a percentage of the notional amount of the option:

We can notice here that the internal model is equivalent to the supervisory 
capital for low maturities however after a maturity of one year we have a tendency towards approximately $80 \%$ of the standardized approach. We note that this might be due to the assumptions taken on the SA-CCR level assuming a $15 \%$ volatility factor whereas the GARCH approach begins by assuming lower observed volatilities on the stressed period (approximately converging towards $13 \%)$ therefore this explains the difference in behaviors depending on the maturities.

\subsubsection{CVA Capital Charge}

Based on Equations ((8)-(10)) we compute the capital charge for the CVA risk under the basic approach, using the following: $\mathrm{RW}=10.2 \%$ considering that the counterpart is a financial institution, $M$ is the effective maturity of the portfolio (here it is below or equal to one year therefore it is equal to one), EAD is the exposure at default computed using the IMM method on a netting set level and $\alpha=1.4$. Table 9 shows the computation for a one-year instrument in each asset type.

The previous table units are as the notional amounts of each instrument type.

The CVA capital charge being a function of the effective maturity and the $\mathrm{EAD}$, we can simply apply the equations on the internally computed EAD on a netting set level in order to get this CVA charge. Having assumed that no hedging is in place for the CVA risk, from Equations ((8)-(10)) applying the coefficients of our cases, we can get the following shortcut formula:

$$
\mathrm{CVA}_{C C}=0.5464 \times M \times \mathrm{EAD}_{I M M}
$$

\subsubsection{Adding Netting and Margin Effects}

Having discussed the benefits of adding netting agreements and margins to our portfolio, in this section we materialize this in an actual calculation for different conditions on three given portfolios. We reconsider the same instruments seen previously, however now we will handle three composed portfolios in order to show the added effect of netting agreements and margin contracts. Trying to consider a hedging set and the effect of choosing between the standardized and internal approach, we consider that in each portfolio all the instruments are held with the same counterparty. Adding to that, we assume the probability of default of the counterparty to be $0.05 \%$ (equivalent to an AA rating).

Portfolio 1: Two IR USD swaps, one long and another short, with maturities 0.5 and 2.5 years and notional amounts of 100 USD each. This consideration was based on the statistics of the IR swaps in the OTC market that reflects the fact that $75 \%$ of the swaps have maturities less than 5 years.

Table 9. CVA capital charge for one year instruments.

\begin{tabular}{cc}
\hline & CVA Capital Charge \\
\hline One year IR swap & 0.047 \\
One year FX forward & 0.47 \\
One year FX call option & 0.12 \\
\hline
\end{tabular}


Portfolio 2: Three FX forwards deals USD/EUR: one long with a residual maturity of 0.5 years and the others short with 1 and 2.5 years' residual maturities. All forwards have the same notional 100 EUR. The choice is also attributed to the distribution of concentration based on maturities in the FX OTC instruments: $<90 \%$ have maturities less than $5 \mathrm{y}$.

Portfolio 3: Two options a long position on a call of 0.5 years as maturity and a short position on another call with a residual maturity of 2.5 years (both have a 100 notional).

Tables 10-12 show respectively the composition of Portfolio 1, 2 and 3.

Not to accumulate numerous variables, we consider the threshold and the minimum transferable amount null. In other words, any positive exposure will trigger the margin agreement. As for the collateral, we implemented ISDA method in order to compute the collateral amount as the 99th percentile of the exposure on a 10-days remargining frequency explained in [18]. No independent amount was considered for the following exercises considering that both counterparties have the same profile therefore the netted collateral value is null. We hold cash collateral. These are our assumptions for the upcoming applications. The frequency term denotes the margin re-evaluation frequency; this criterion will define the maturity factor used to compute the exposure at default under the standardized approach (refer to paragraph Potential future exposure p.17). In general, daily frequencies are used therefore we applied this on our portfolios and used the 10 days MPOR amended by Basel for such remargining frequency. Applying all the above, summaries for the margin agreement are found in Tables 13-15.

Table 10. Portfolio 1 composition.

\begin{tabular}{ccccccc}
\hline Trade & Type & Currency & Position & Notional & $\begin{array}{c}\text { Residual } \\
\text { Maturity }\end{array}$ & MtM0 \\
\hline 1 & IR swap & USD & Short & 100 & 0.5 & 0 \\
2 & IR swap & USD & long & 100 & 2.5 & 0 \\
\hline
\end{tabular}

Table 11. Portfolio 2 composition.

\begin{tabular}{ccccccc}
\hline Trade & Type & Currency & Position & Notional & $\begin{array}{c}\text { Residual } \\
\text { Maturity }\end{array}$ & MtM0 \\
\hline 1 & FX forward & USD/EUR & Short & 100 & 0.5 & 0 \\
2 & FX forward & USD/EUR & long & 100 & 1 & 0 \\
3 & FX forward & USD/EUR & long & 100 & 2.5 & 0 \\
\hline
\end{tabular}

Table 12. Portfolio 3 composition.

\begin{tabular}{ccccccc}
\hline Trade & Type & Currency & Position & Notional & $\begin{array}{c}\text { Residual } \\
\text { Maturity }\end{array}$ & MtM0 \\
\hline 1 & FX option call & USD/EUR & Short & 100 & 0.5 & -0.03 \\
2 & FX option call & USD/EUR & long & 100 & 2.5 & 1.07 \\
\hline
\end{tabular}


Table 13. Portfolio 1 margin agreement.

\begin{tabular}{ccccc}
\hline Frequency & Threshold & MTA & Independent Amount & Net Collateral \\
\hline Daily & 0 & 0 & 0 & 0.12 \\
\hline
\end{tabular}

Table 14. Portfolio 2 margin agreement.

\begin{tabular}{rrrrr}
\hline Frequency & Threshold & MTA & Independent Amount & Net Collateral \\
\hline Daily & 0 & 0 & 0 & 1.48 \\
\hline
\end{tabular}

Table 15. Portfolio 3 margin agreement.

\begin{tabular}{ccccc}
\hline Frequency & Threshold & MTA & Independent Amount & Net Collateral \\
\hline Daily & 0 & 0 & 0 & 0.80 \\
\hline
\end{tabular}

\section{Default capital charge}

\section{Portfolio 1}

- Step 1: Netting but no margin. A simple summation of the exposures at default of the previously computed results in the non-netted results. For the netting sets, SA-CCR formula for the IR class amends an aggregation of the effective notional in such a way to account for different maturity buckets:

$$
\begin{aligned}
& \text { Effective notional } \\
& =\sqrt{\mathrm{Eff} \cdot \text { notional }_{1}^{2}+\mathrm{Eff} \cdot \text { notional }_{2}^{2}+1.4 \mathrm{Eff} \cdot \text { notional }_{1} \mathrm{Eff} \cdot \text { notional }_{2}}
\end{aligned}
$$

This is specified by the correlation parameters supposed by Basel between maturity buckets in the IR asset type (cf. BCBS (2014b) paragraph 4.1). The internal model is less demanding than the SA-CCR in both cases (netted or not). However, the netting effect decreases the exposure of the SA-CCR by an average rate of $22 \%$ whereas the IMM only decreases by $7 \%$.

- Step 2: Margin but no netting. Applying the conditions of the margin agreement cited previously on each of the trades in the portfolio, we compute the EAD for un-netted but margined portfolio. For the SA-CCR approach, the RC follows Equation (4) and the maturity factor is restrained because we have a daily computation (MPOR $=10)$. For the IMM, the EAD was recomputed following the margin agreement. When the collateral increases, the EAD decreases. We can notice that both methods decreased the capital charge by $72 \%$. Note the importance of the maturity factor change: In the SA-CCR the MF is dependent of the MPOR chosen amended as 10 days for the daily margin. For the IMM, the 1.5 factor added in the SA-CCR is translated as a different MPOR for the IMM: $1.5 \times 1.5 \times 10$ therefore applying the IMM margin agreement with a MPOR of 22.5 days would be coherent with the standardized method. If we chose to add only a margin agreement with daily remargining, no collateral, no threshold, no initial margin nor minimum transferable amount, the SA-CCR EAD would be reduced by $67 \%$ (from the initial EAD "nothing"). With the collateral addition, the SA-CCR reduces the capital charge by $72.8 \%$ whereas the IMM by $72.3 \%$ retaining the 
ratio between the IMM to the SA-CCR EAD at 78\%.

- Step 3: Netting and margin. As a final step we merge collateral and netting agreement to compute the capital charge.

Figure 13 resumes the EAD of Portfolio 1 under several conditions:

Portfolio 2

- Step 1: Netting but no margin. For the netting sets, SA-CCR formula for the FX class amends the absolute value of the aggregation of effective notional following:

$$
\text { Effective notional }=\mid \text { Eff } \cdot \text { notional }_{1}+\text { Eff } \cdot \text { notional }_{2}+\text { Eff } \cdot \text { notional }_{3} \mid
$$

The internal model is less demanding than the SA-CCR in the non-netted and almost equivalent in the netted portfolios however, not by much: the netting effect is more recognized in the SA-CCR. In terms of ratios, the EAD decreases the standard exposure by a rate of $52 \%$ whereas it decreases the IMM EAD by $38 \%$.

- Step 2: Margin but no netting. As for step 2, the needed modifications are put in place to recomputed the EAD for the standardized approach. For both models, the margin agreement decreased the EAD (therefore the capital charge) by almost the same amount: 79\% in SA-CCR and 77\% in IMM.

- Step 3: Netting and margin. Merging collateral and netting agreement.

Figure 14 resumes the EAD of Portfolio 2 under several conditions:

Portfolio 3

Step 1: Netting but no margin. This portfolio is also in the FX bucket therefore the same computation as portfolio 2 is used in order to define the EAD of the whole portfolio under the SA-CCR approach. The internal model reflects the SA-CCR behavior in terms of reduction: the netting effect reduces EAD by $16 \%$ in the SA-CCR and in the IMM.

- Step 2: Margin but no netting. For the SA-CCR the EAD computation re-

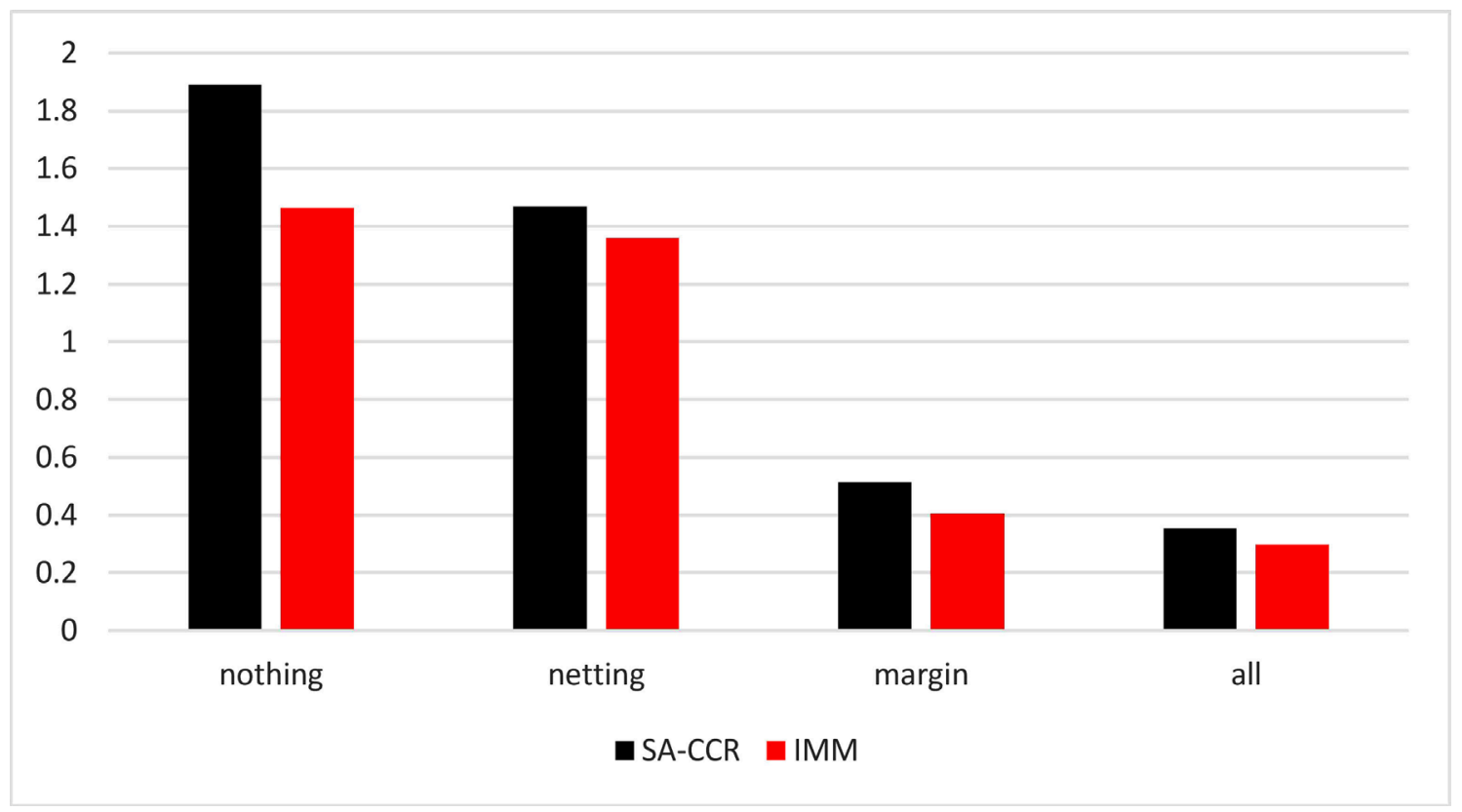

Figure 13. Capital charge portfolio 1 . 


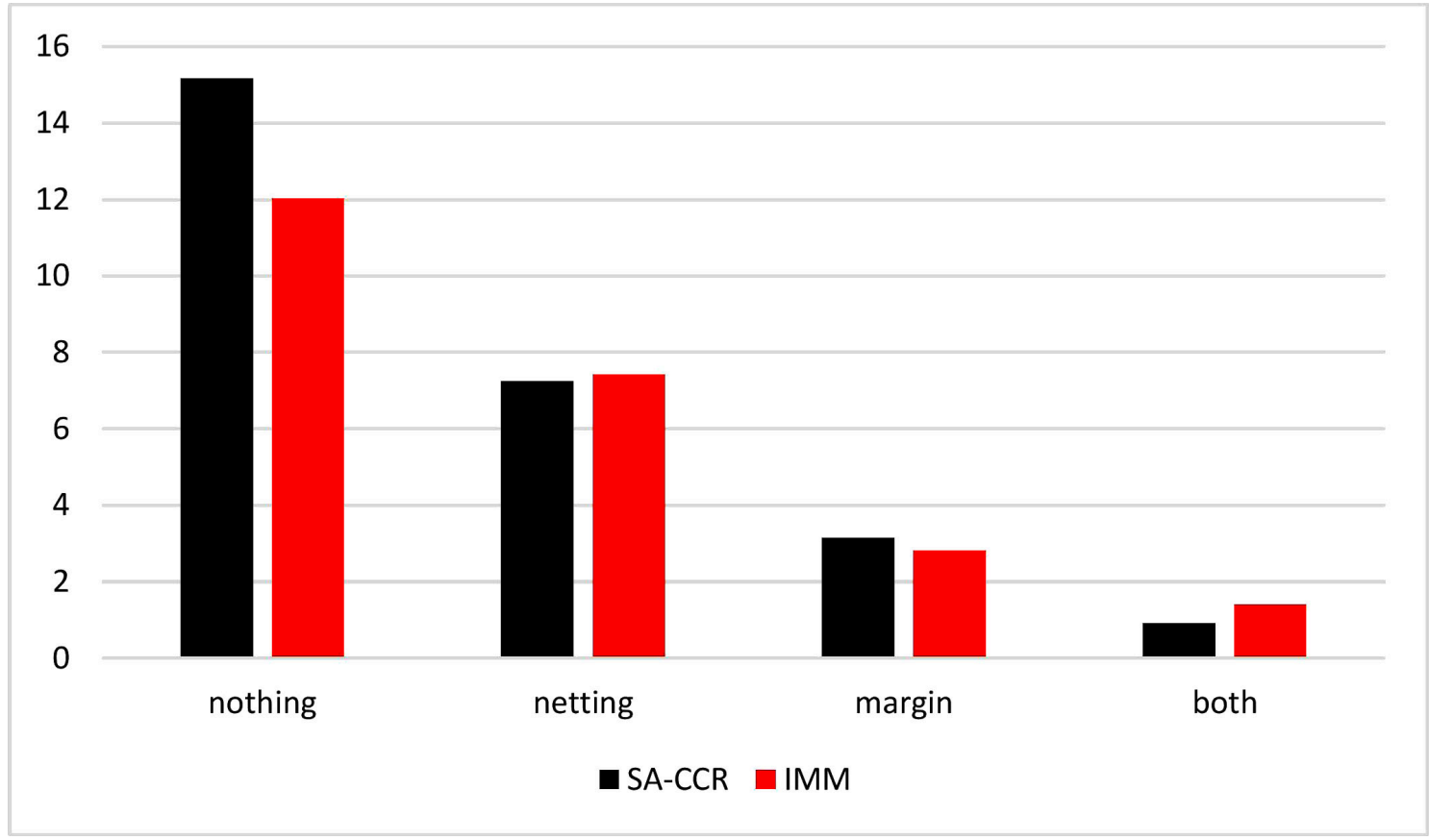

Figure 14. Capital charge portfolio 2.

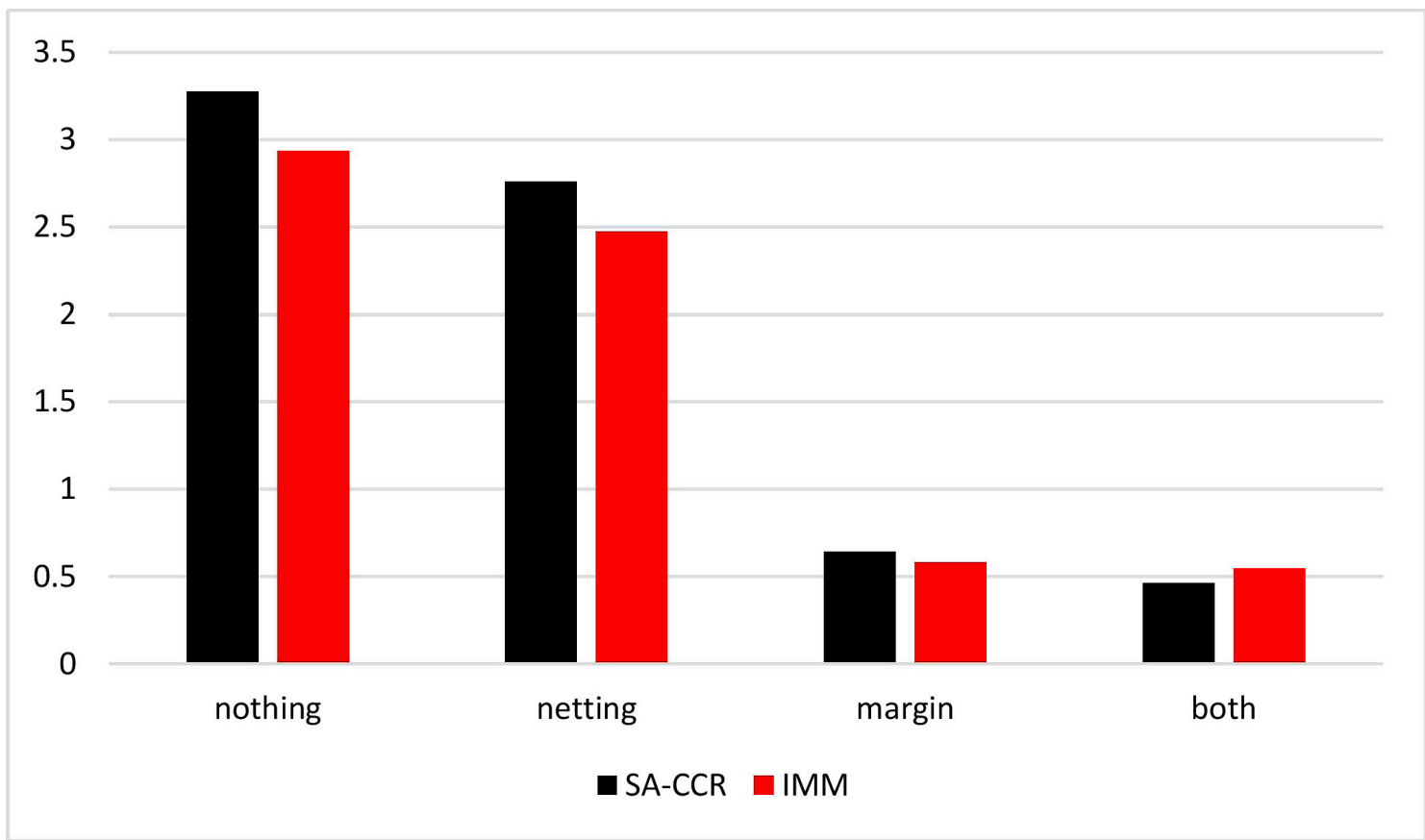

Figure 15. Capital charge portfolio 3.

sults in lower EAD, as estimated, the collateral will amply reduce the amount of the EAD: $80 \%$ SA-CCR and $81 \%$ IMM.

- Step 3: Netting and margin. Merging collateral and netting agreement in order to compute the capital charge of our portfolio.

Figure 15 resumes the EAD of Portfolio 3 under several conditions: CVA capital charge

Applying Equations ((7) to (11)) we compute the basic CVA capital charge. 
We apply the computation on the previously considered portfolios: Portfolio 1, 2 and 3.

Considering that the counterparty we considered is a financial institution, the RW amended by Basel for this CVA approach would be 5\%. Not having any hedging, Table 16 demonstrate the CVA capital charge deducted following Equation (12) denoted earlier.

\section{iv. Comparative Analysis}

- Default Capital Charge:

Starting our comparison with the default capital charge section, we need to compare the IMM to the SA-CCR on the three portfolios level:

- SA-CCR: Focusing on the SA-CCR we have to emphasis the importance of netting and margin agreements:

The EAD amounts reflected in Table 17 is for the standardized approach applied on the three portfolios (portfolio 1 the IR swaps, portfolio 2 the FX forwards and portfolio 3 the FX options). Trying to make sense of these variations, Table 18 presents the ratios of the EAD for each portfolio over the EAD not having any collateral or netting (the "nothing" case).

In order to interpret the results, we will divide this table twice: once based on the portfolio therefore on the asset typologies, and another time based on the hedging strategies added (netting, margin agreements, none or both).

We start by discussing the results based on the asset types: For the IR type (portfolio 1), the EAD decreases by $20 \%$ upon applying netting agreements: this

Table 16. CVA capital charge.

\begin{tabular}{lc}
\hline & CVA capital charge \\
\hline Portfolio 1 & 0.370 \\
Portfolio 2 & 2.025 \\
Portfolio 3 & 0.626 \\
\hline
\end{tabular}

Table 17. EAD under the SA-CCR.

\begin{tabular}{cccc}
\hline & Portfolio 1 & Portfolio 2 & Portfolio 3 \\
\hline nothing & 1.889 & 15.159 & 3.275 \\
netting & 1.484 & 7.240 & 2.758 \\
margin & 0.433 & 3.135 & 0.641 \\
both & 0.293 & 0.915 & 0.464 \\
\hline
\end{tabular}

Table 18. EAD percentage of the "nothing" case.

\begin{tabular}{cccc}
\hline & Portfolio 1 & Portfolio 2 & Portfolio 3 \\
\hline nothing & $100 \%$ & $100 \%$ & $100 \%$ \\
netting & $79 \%$ & $48 \%$ & $84 \%$ \\
margin & $23 \%$ & $21 \%$ & $20 \%$ \\
both & $15 \%$ & $6 \%$ & $14 \%$ \\
\hline
\end{tabular}


is due to the fact that the notional amount is reduced when aggregated (Equation (15)) and bucketing is taken into account under the SA-CCR method. Regarding the margin additions change is due to the collateral add-ons and the maturity factors change: even if we do not add any collateral amount, having a margining agreement with daily frequency and the given threshold and MTA, the EAD will decrease per example in the netting case by $70 \%$ due to the change in the maturity factor. Then again adding the collateral will reduce the multiplier to less than 1 in order to reflect the collaterization effect reducing furthermore the EAD figure by almost $80 \%$. When having only a collateral (and no netting), $75 \%$ reduction is observed and finally when having both hedging policies in place the reduction will increase to be $85 \%$ which is coherent with Basel suggestions that with adequate hedging techniques the capital charge could be reduced up till 90\%. The FX typology is seen in Portfolio 2 and Portfolio 3: Grosso modo we can see that the impact of netting sets in this asset type is depending on the portfolios: for portfolio 2 we have three instruments where in portfolio 3 we have a strategy resembling portfolio 1 therefore the effect of netting here could be compared to the $80 \%$ observed in portfolio 1 whereas the impact is much higher for portfolio 2. One explanation of such differences might be the method of computation for the netting set effective notional on one hand (Equation (16)) and for the fact that in this bucket maturities are not really considered therefore this could be applied for any maturities (going form 10 days up till five years). Netting reduces the exposure to a half, and the collateral to $20 \%$ in portfolio 2 and $80 \%$ and $20 \%$ under portfolio 3, whereas when applying both hedges the reduction is much more important hitting $95 \%$ for Portfolio 2 and $85 \%$ for Portfolio 3.

Based on hedging techniques applied, we discuss the following: Across all portfolios, the results of the netting techniques are various: for the first portfolio, the netting permitted a reduction of $20 \%$ whereas this reduction was far higher for the second portfolio $60 \%$ then again a $15 \%$ for the third one. Margining also had different impacts however, having chosen to suppose a collateral that covers the 99\% percentile exposure, the important reduction was the expected and homogeneous between all portfolios: an average of $80 \%$ reduction. The last case is having both margin and netting applied, this results in a $15 \%$ for the IR portfolio, $6 \%$ for the FX forward portfolio and 14\% for the FX option portfolio.

- IMM: Only analyzing the internal model based on the same approach previously applied for the SA-CCR results in Table 19 figures in term of EAD:

Table 20 is the same table in percentage of the non-hedged portfolios EAD:

A similar look to this table could show the differences of impact between the two assets types and the additional difference between instruments with or without optionality.

- SA-CCR vs IMM: Comparing the IMM to SA-CCR, as per Table 21, several remarks could be presented, in order to facilitate the representation, the following table sets the ratios of the IMM required capital to the SA-CCR required capital in the same category: 
Table 19. EAD under the IMM

\begin{tabular}{cccc}
\hline & Portfolio 1 & Portfolio 2 & Portfolio 3 \\
\hline nothing & 1.463 & 12.030 & 2.936 \\
netting & 1.354 & 7.413 & 2.473 \\
margin & 0.263 & 2.811 & 0.581 \\
both & 0.200 & 1.399 & 0.547 \\
\hline
\end{tabular}

Table 20. EAD percentage of the "nothing" case.

\begin{tabular}{cccc}
\hline & Portfolio 1 & Portfolio 2 & Portfolio 3 \\
\hline nothing & $100 \%$ & $100 \%$ & $100 \%$ \\
netting & $93 \%$ & $62 \%$ & $84 \%$ \\
margin & $18 \%$ & $23 \%$ & $20 \%$ \\
both & $14 \%$ & $12 \%$ & $19 \%$ \\
\hline
\end{tabular}

Table 21. EAD ratio IMM/SA-CCR.

\begin{tabular}{cccc}
\hline IMM/SA-CCR & Portfolio 1 & Portfolio 2 & Portfolio 3 \\
\hline nothing & $77 \%$ & $79 \%$ & $90 \%$ \\
netting & $91 \%$ & $102 \%$ & $90 \%$ \\
margin & $61 \%$ & $90 \%$ & $91 \%$ \\
both & $68 \%$ & $153 \%$ & $118 \%$ \\
\hline
\end{tabular}

Based on assets' type, we discuss the following:

- Portfolio 1 shows that: the IMM is less demanding than the SA-CCR in all scenarios and along with the entity of hedging techniques. This could be interpreted by several causes: the restrictive 5\% floor in the multiplier of the standardized approach or the supervisory factor of $0.5 \%$ intended to reflect the one-year volatility of the rates and which is a bit too restrictive for our USD case. In the case of margining and netting addition (when applying both techniques) the IMM always amends less capital.

- Portfolio 2 reflects a different ideology. Not applying neither netting nor collateral, the IMM represents $80 \%$ of the SA-CCR EAD, adding the netting our IMM converges away from the SA-CCR figure (such was not the case in Portfolio 1 but here the computation of the netting sets differs in the SA-CCR) and amends similar capital requirements. When adding the margin agreement only, our model is less demanding by (representing only $90 \%$ ). Last step, netting and margining the portfolio would result, in a more easy-going SA-CCR in a sort that the IMM requests the standardized capital times 1.5. This could be interpreted by the motivation given by Basel to apply such techniques therefore by the important reduction in the standardized model making the IMM much more demanding.

- Portfolio 3 slightly differs from the previous portfolios due to the effect of the optionality on the netting and margining computations: having the SA-CCR 
recommending less capital charges for optionality embedded instruments, our internal model seems to be a bit too restrictive. No hedging implies a 90\% capital charge (IMM to EAD) and applying both methods would result in a $118 \%$. We can deduce that for the FX options portfolio, the SA-CCR is less demanding than our internal model and requires a lower capital charge. Plus, we note that this is applied for the EUR-USD FX pair with an initial volatility of $13 \%$ in our internal models (increasing) whereas Basel amends a $15 \%$ volatility factor.

Based on hedging techniques applied, we discuss the following:

- When nothing is applied, our internal model is representing $80 \%$ of the SA-CCR figures.

- Netting effects vary between portfolios depending on the composition of each: in the IR and FX options where we net a 2.5 years by a 0.5 years' instrument, the capital charge decreases by $10 \%$. However, in the second portfolio the SA-CCR was less demanding (a ratio of 102\%).

- The margin agreement effect was more recognized in the IR swap due to the low fluctuations of such instruments (re-evaluated quarterly) making the IMM equal to only $60 \%$ of the standardized figure. On another hand, in the FX portfolios, the fluctuations were considered through the lower and higher bonds of the margin agreement reducing more significantly the demanded capital charge (up to $90 \%$ ).

- Finally, having both effects, Basel "rewards" such techniques and reduces the capital in a way that makes our IMM more demanding than the SA-CCR for the FX bucket. This is expected because one motivation of this new SA-CCR is to motivate banks to margin and net their deals.

CVA Capital Charge: In terms of ratio, Table 22 resumes the results:

For the singular portfolios, having an effective maturity of one year the ratio is constant and equal approximately to $55 \%$ to $65 \%$ for the default counterparty capital charge therefore doubling the capital charge for the counterparty credit risk. For the mixed portfolios, the add-on of the CVA capital charge depends on the effective maturity and the EAD therefore, for our considered example, the capital charge of the CVA consists of around $55 \%$ to $58 \%$ of the total counterparty capital requirement resulting in an additional $20 \%$ to $30 \%$ on the default capital charge amount amended in earlier version of Basel requirements.

Table 22. Capital charge ratio of total counterparty credit risk.

\begin{tabular}{cccc}
\hline & CVA Capital Charge & CCR netting without collateral & CVA/CCR \\
\hline Singular 1 & $35.33 \%$ & $64.67 \%$ & 0.54 \\
Singular 2 & $35.33 \%$ & $64.67 \%$ & 0.54 \\
Singular 3 & $35.33 \%$ & $64.67 \%$ & 0.54 \\
Portfolio 1 & $57.74 \%$ & $42.26 \%$ & 1.36 \\
Portfolio 2 & $56.32 \%$ & $43.67 \%$ & 1.29 \\
Portfolio 3 & $55.87 \%$ & $44.13 \%$ & 1.27 \\
\hline
\end{tabular}




\section{Conclusions}

This work permits comparison between the standardized approaches used by Basel and suggests internal model methodology based on historical and futuristic observations through various applications on simple portfolios. After having demonstrated the process of each of the internal and standardize approaches, the applications showed a convergence between these two and highlighted the conditions that allow one method to be more restrictive than the other.

CVA risk adds a large weight to the capital requirement as expected, however its computation depends highly on the risk type that we are handling and the effective maturity of the portfolios. As for the SA-CCR, our work showed a tendency to encourage banks into hedging techniques especially margin agreements through reducing the capital charge amended when such practices are in place.

For the interest rate swap we deduct that the model chosen is less demanding than the Basel approach: On a first hand, when no hedging techniques is there, the model is representative at $80 \%$ for such maturities (up to 2.5 years). When adding netting the percentage increases to $90 \%$; therefore the recognition of the netting effect is much more rewarded by Basel. On the second hand, when margin agreement is in place our model requests only $60 \%$ of Basel's capital and when netted is added the same effect as a non-margined portfolio. This is due to the computation of the margined portfolio capital charge in the interest rate bucket which includes decreasing the multiplier affecting the EAD resulting in reducing the total charge.

As for the foreign exchange assets types, we have different behaviors depending on the presence of optionality or not. When not handling optionality (in portfolio 2 with FX forwards), the internal model under no netting neither margin agreements represents $80 \%$ of the EAD under the SA-CCR. Netting added, the internal model diverges from the standardized approach and requires 102\% of the SA-CCR capital charge. Again, with no netting however adding a collateral the ratio increases to $90 \%$ and finally when margin and netting are there the IMM EAD represents $150 \%$ of the SA-CCR EAD due to the benefits added in the Basel approach in order to reward netting and margining agreements (which is not really "rewarded" in the Internal Model).

Handling the last portfolio, FX bucket under optionality, the conclusions differ a bit: In no netting no margin environment the IMM is a bit less demanding than the SA-CCR (by 10\%) of the EAD this is due to the volatility factor amended by Basel (15\%) which does not reflect the volatility of the FX currency we considered (going from $14 \%$ up till $17 \%$ in GARCH approach volatility).

This is permitted for the standardized approach as it tries to cover all currencies therefore could not be more indulgent in terms of amended volatility however, this might be modified a little if Basel considered assigning different volatilities for different FX currency pairs in the options types. When netting, due to the hypothesis of daily re-margin and the specificity in computing the EAD under the SA-CCR for optionality-included instruments, the equilibrium is not bothered and the EAD under both methods remains 90\%. Applying both tech- 
niques, once again Basel rewards the bank and reduces its capital requirement making the ratio of the internally amended capital charge to the standardized one equal to $118 \%$. Again, this is another example on how the standardized approach is rooting for the margin and netting agreements.

A model based on experts' opinion and future market estimations, even if calibrated on stressed historically observed data, showed as a differing capital amendment than the one demanded by Basel. Logical interpretation could be presented and reasonable choices could be made: Basel requires a standardized figure not accounting for the currency of the instrument should be "generalized" whereas our internal model is calibrated to the volatility, historical jumps, future forecasting... of a given market therefore in some cases could be more beneficial or more restrictive than the standardized EAD figure. In this paper examples on EUR and USD instruments clarified the common and different points of the two possible approaches to highlight this divergence or convergence between what banks could choose to use. In parallel, the suggested models and calibrations are a logical "mix" between the history and the future horizons trying to create a complete figure of the market.

The last remark would be on the CVA capital charge, Basel is encouraging banks to pass the deals to central clearing houses: in doing so no CVA capital charge would be amended, after seeing the huge impact of the CVA capital charge on the total counterparty capital charge we can deduct why banks are all converging towards clearing their portfolios through trusted clearing houses, a question on the stability and coherent risk management of these clearing houses remain questionable in such cases.

This work aimed to offer a detailed view of the counterparty risk capital charge handling in the banking sector through a description and interpretation of the standardized amended methodologies and by presenting and contrasting an internal model that is able to reflect both historical behaviors and future expert estimations. The internal approach is mostly less demanding to banks and reflects in a better perspective their workflow however, we should note that our results are highly depended of the portfolios we choose and the currency we handled. This should be noted for further works. In addition, the CVA was tackled without considering the wrong way risk (WWR) not to make the paper any more computationally heavy, however the WWR which is the correlation between the exposures and the probability of default of the counterparty, this will have an important impact on the CVA capital charge computation and in practice should not be neglected. Our next work will incorporate this variable into the computation in order to measure its impact on the CVA capital charge.

\section{Acknowledgements}

This work is funded as part of my PhD thesis by the National Council for Scientific Research of Lebanon (CNRS-L) and Bank Audi s.a.l. However, the information and views set out in this article are those of the author and do not reflect the official opinion of Bank Audi. 


\section{References}

[1] Beier, N., Harreis, H., Poppensieker, T., Sojka, D. and Thaten, M. (2010) Getting to Grips with Counterparty Risk. Mc Kinsey Working Papers on Risk, No. 20.

[2] Ingves, S. (2013) Regulatory Reforms for OTC Derivatives: Past, Present and Future. Banque de France, Financial Stability Review, No. 17, 19-28.

[3] Basel Committee on Banking Supervision (BCBS) (2010) Basel III: A Global Regulatory Framework for More Resilient Banks and Banking Systems.

[4] CRDIV Framework, 2014, Credit Valuation Adjustment (CVA).

[5] Basel Committee on Banking Supervision (BCBS) (2014) The Standardized Approach for Measuring Counterparty Credit Risk Exposures.

[6] FEI A. (2014) Overview of Basel Committees Standardized Approach for Measuring Derivatives Exposure.

[7] Basel Committee on Banking Supervision (BCBS) (2014) Foundations of the Standardized Approach for Measuring Counterparty Credit Risk.

[8] Basel Committee on Banking Supervision (BCBS) (2016) Reducing Variation in Credit Risk-Weighted Assets: Constraints on the Use of Internal Model Approaches. Consultative Document, March 2016.

[9] Pykhtin, M. and Zhu, S. (2007) A Guide to Modelling Counterparty Credit Risk. Global Association of Risk Professionals, July/August 2007 Issue.

[10] Basel Committee on Banking Supervision (2015) Regulatory Consistency Assessment Program, Report on Risk-Weighted Assets for Counterparty Credit Risk.

[11] Gregory, J. (2015) Linking FRTB with CVA Capital. WBS FRTB Conference, London.

[12] Basel Committee on Banking Supervision (BCBS) (2015) Review of the Credit Valuation Adjustment Risk Framework. Consultative Document.

[13] Basel Committee on Banking Supervision, 2016, Instructions: CVA QIS.

[14] Basel Statistical Release (BIS) (2015) OTC Derivatives Statistics at End-June 2015. Monetary and Economic Department, Basel.

[15] Nielsen, L. (1993) Understanding N (d1) and N (d2): Risk-Adjusted Probabilities in the Black-Scholes Model. Finance, 14, 95-106.

[16] FOMC (2015) Federal Open Market Committee Economic Projections for December 2015. www.federalreserve.gov

[17] Planchet, F. and Karam, E. (2013) Estimation Errors and SCR Calculation. Bulletin Français d' Actuariat, 13, 79-92.

[18] ISDA (2013) International Swaps and Derivatives Association, Standard Initial Margin Model for Non-Cleared Derivatives. 


\section{Appendix}

\section{Appendix 1: Supervisory Duration}

In the Basel document, one component for determining the $\mathrm{EAD}$ of an interest rate class instrument is the supervisory duration. In this computation we aim to understand the hypothesis lying behind the choice of such factor.

The given formula is the following:

$$
S D=\frac{\mathrm{e}^{-0.05 S}-\mathrm{e}^{-0.05 E}}{0.05}
$$

If we consider a bond with a starting date $S$ and an ending date $E$, paying coupons of rate $\alpha$ and having a yield to maturity YTM equal to $\alpha$; the valuation of this bond's duration in a continuous fashion will result in the following:

$$
\text { Duration }=\frac{\int_{0}^{E-S} \alpha t \mathrm{e}^{-\alpha t} \mathrm{~d} t+(E-S) \mathrm{e}^{-\alpha(E-S)}}{\int_{0}^{E-S} \alpha \mathrm{e}^{-\alpha t} \mathrm{~d} t+\mathrm{e}^{-\alpha(E-S)}} \times \mathrm{e}^{-\alpha S}
$$

Using an integration by parts process, the previous equation results in the following:

$$
\begin{gathered}
\text { Duration }=\frac{\left[-t \mathrm{e}^{-\alpha t}\right]_{0}^{E-S}+\int_{0}^{E-S} \mathrm{e}^{\alpha t} \mathrm{~d} t+(E-S) \mathrm{e}^{-\alpha(E-S)}}{-\left[\mathrm{e}^{-\alpha t}\right]_{0}^{E-S}+\mathrm{e}^{-\alpha(E-S)}} \\
\text { Duration }=\frac{\left(-(E-S) \mathrm{e}^{-\alpha(E-S)}\right)-\frac{1}{\alpha}\left(-\mathrm{e}^{-\alpha 0}+\mathrm{e}^{-\alpha(E-S)}\right)+(E-S) \mathrm{e}^{-\alpha(E-S)}}{\alpha \mathrm{e}^{\alpha S}} \\
\text { Duration }=\frac{1-\mathrm{e}^{-\alpha(E-S)}}{\alpha \mathrm{e}^{\alpha S}} \\
\text { Duration }=\frac{\mathrm{e}^{\alpha S}-\mathrm{e}^{-\alpha E}}{\alpha}
\end{gathered}
$$

Replacing the $\alpha$ factor by 0.05 or $5 \%$ we obtain the supervisory duration in Equation (3).

The duration is an indication of the instrument's maturity because the maturity is capped at one year, therefore the necessity of the incorporation of that factor.

\section{Appendix 2: Data Used}

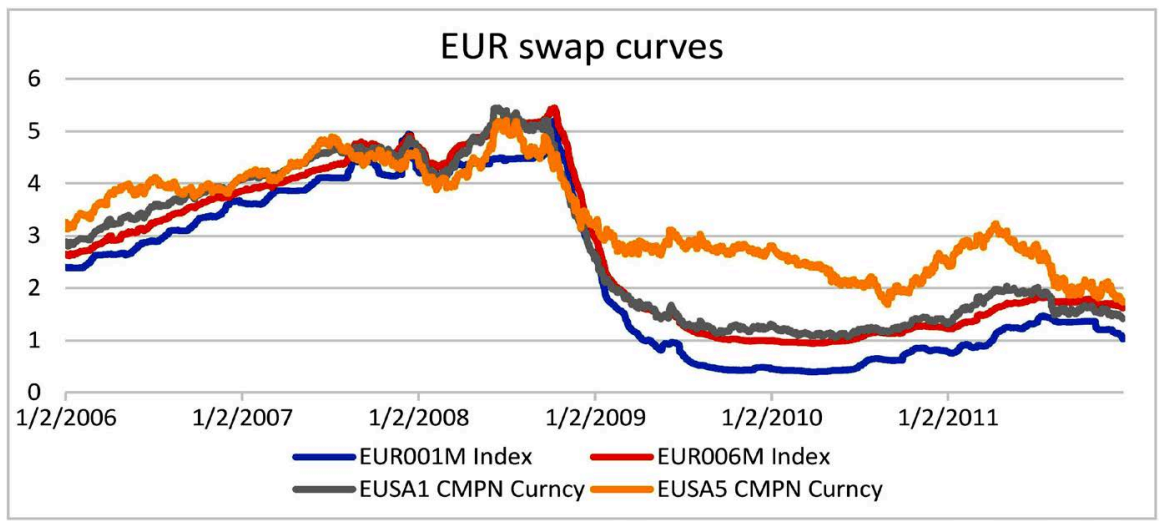

Figure S1. Historical Euro swap rates for $1 \mathrm{~m}, 6 \mathrm{~m}, 1 \mathrm{y}$ and $5 \mathrm{y}$. 


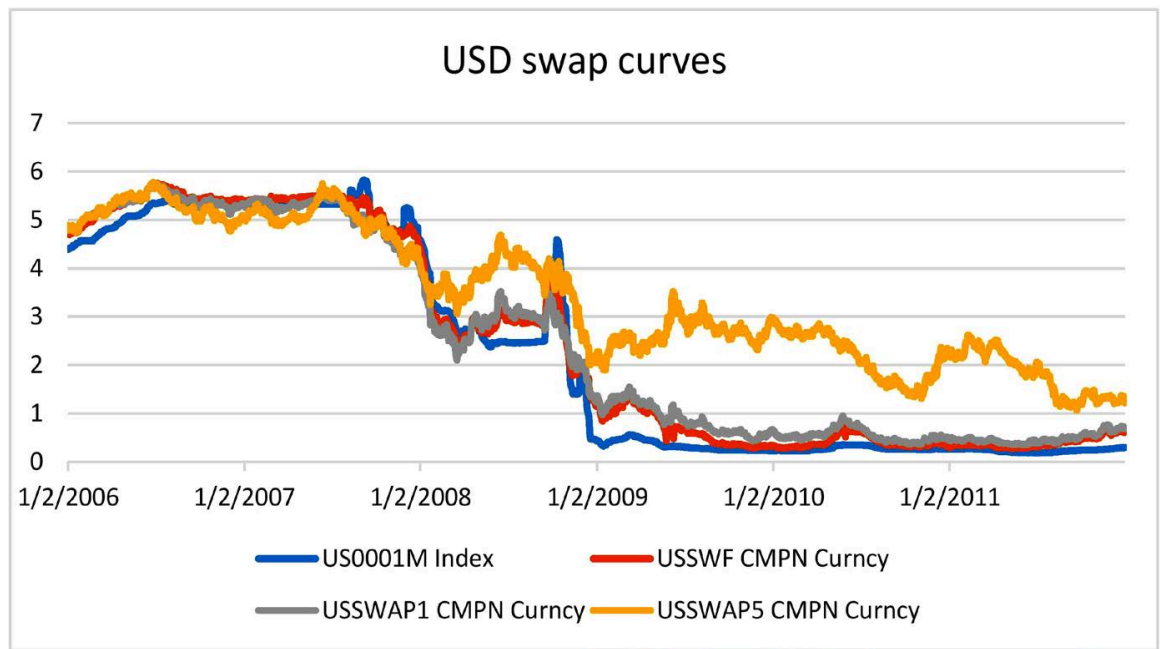

Figure S2. Historical USD swap rates for $1 \mathrm{~m}, 6 \mathrm{~m}, 1 \mathrm{y}$ and $5 \mathrm{y}$.

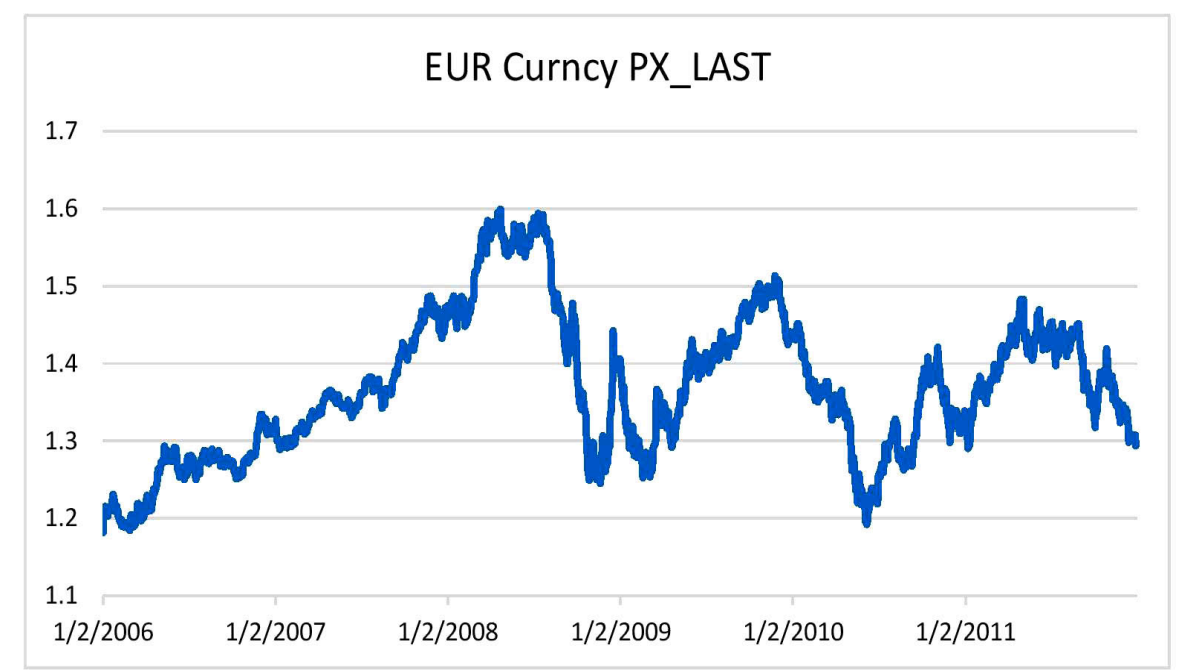

Figure S3. Historical FX spot rate.

\section{Appendix 3: Vasicek Model Implementation}

The work on Vasicek model was based on the paper by Planchet and Karam (2013):

Vasicek discretization formula:

$$
\begin{gathered}
r_{t+\delta}=r_{t} \mathrm{e}^{-k \delta}+\theta\left(1-\mathrm{e}^{-k \delta}\right)+\sigma \sqrt{\frac{1-\mathrm{e}^{-2 k \delta}}{2 k}} \epsilon_{k} \quad \text { Estimating the parameters: } \\
\hat{k}=-\frac{1}{\delta} \ln (\hat{\beta}) \\
\hat{\beta}=\frac{n \sum_{i=1}^{n} r_{i} r_{i-1}-\sum_{i=1}^{n} r_{i} \sum_{i=1}^{n} r_{i-1}}{n \sum_{i=1}^{n} r_{i-1}^{2}-\left(\sum_{i=1}^{n} r_{i-1}\right)^{2}} \\
\hat{\theta}=\frac{\sum_{i=1}^{n}\left(r_{i}-\hat{\beta} r_{i-1}\right)}{n(1-\hat{\beta})}
\end{gathered}
$$




$$
\begin{gathered}
\hat{\sigma}=\sqrt{\frac{\frac{1}{n} \sum_{i=1}^{n}\left[r_{i}-\hat{\beta} r_{i-1}-\hat{\theta}(1-\hat{\beta})\right]^{2}}{\frac{1-\mathrm{e}^{-2 k \delta}}{2 k}}} \\
\left.\lambda=\frac{\left(\left(\theta-\frac{\sigma^{2}}{2 k^{2}}\right)-\left(\frac{\left(\frac{\sigma^{2}}{4 k} B(0, T)+r_{0}\right) B(0, T)+\ln (P(0, T))}{B(0, T)-T}\right)\right) k}{\sigma}\right)
\end{gathered}
$$

And getting the yield we apply the following:

$$
\begin{gathered}
R(t, T)=-\frac{\ln (P(t, T))}{T-t} \\
P(t, T)=A(t, T) \mathrm{e}^{\{-B(t, T) r(t)\}} \\
A(t, T)=\exp \left[\left(\theta-\frac{\sigma \lambda}{k}-\frac{\sigma^{2}}{2 k^{2}}\right)(B(t, T)-(T-t))-\frac{\sigma^{2}}{4 k} B(t, T)^{2}\right. \\
B(t, T)=\frac{1-\mathrm{e}^{-k(T-t)}}{k}
\end{gathered}
$$

\section{Appendix 4: GARCH Model Parameters}

Garch $(1,1)$ normal conditions:

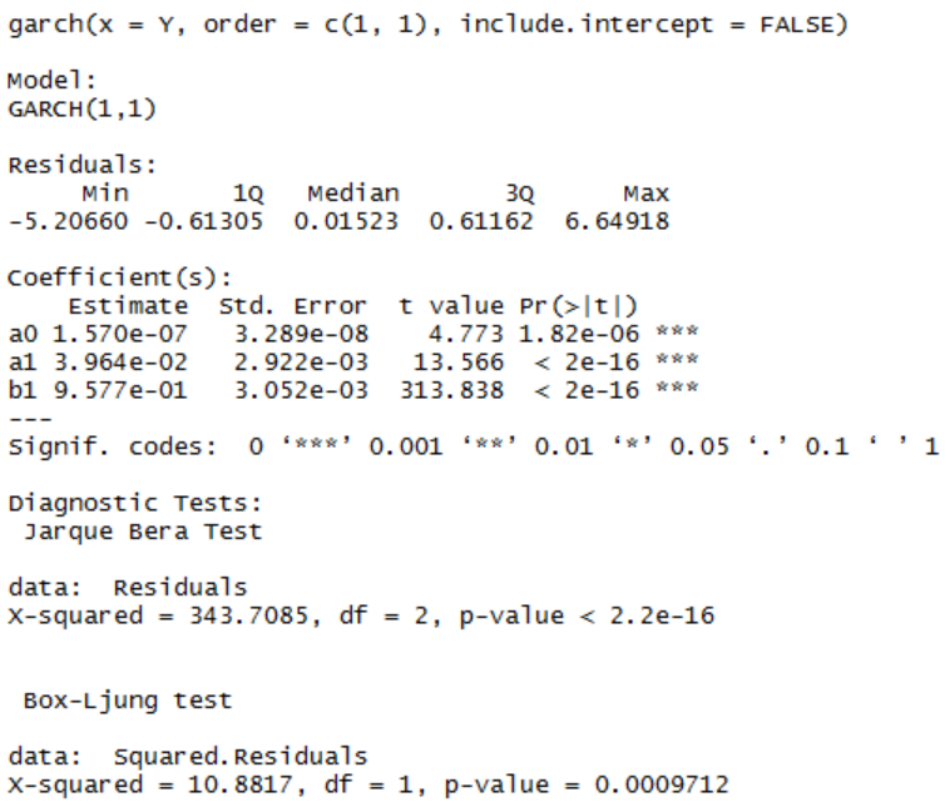

Figure S4. GARCH for EUR/USD FX on the normal market conditions. 
Garch $(1,1)$ stressed conditions:

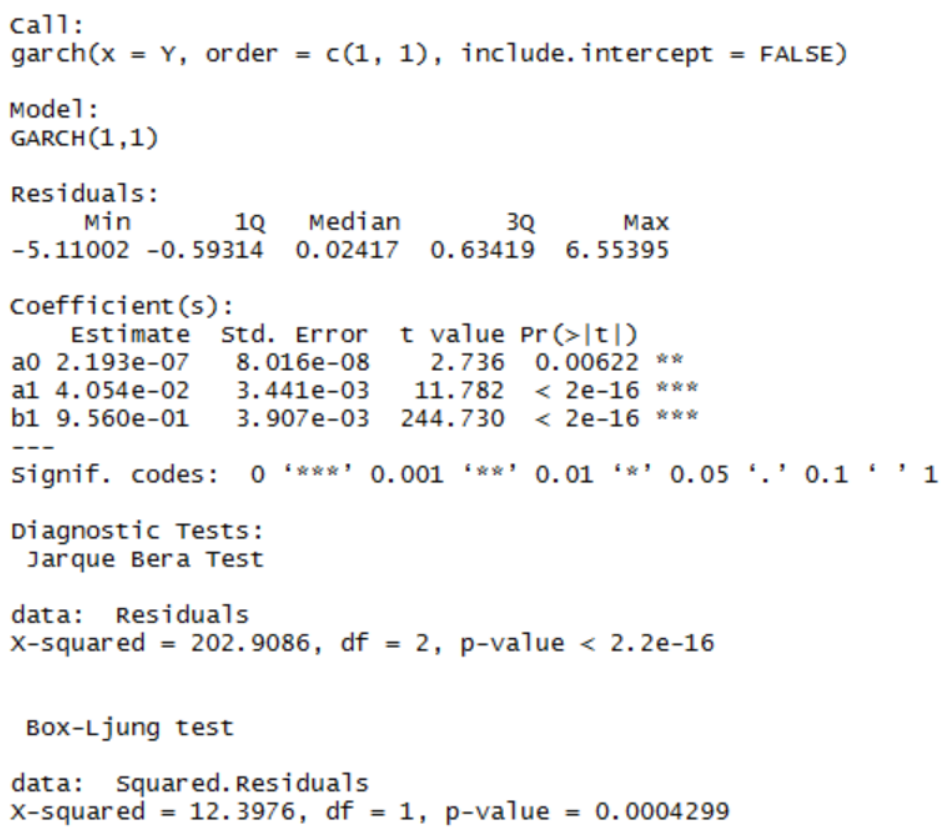

Figure S5. GARCH for EUR/USD FX on the stressed market conditions.

Submit or recommend next manuscript to SCIRP and we will provide best service for you:

Accepting pre-submission inquiries through Email, Facebook, LinkedIn, Twitter, etc. A wide selection of journals (inclusive of 9 subjects, more than 200 journals) Providing 24-hour high-quality service User-friendly online submission system Fair and swift peer-review system Efficient typesetting and proofreading procedure Display of the result of downloads and visits, as well as the number of cited articles Maximum dissemination of your research work

Submit your manuscript at: http://papersubmission.scirp.org/ Or contact jimf@scirp.org 